\title{
0 Efeito da Desigualdade da Distribuição de Renda no Crescimento Econômico
}

\author{
Poliano Bastos da Cruz ${ }^{*}$, Arilton Teixeira ${ }^{\dagger}$, Danilo Soares Monte-Mor ${ }^{\ddagger}$
}

\author{
Sumário: 1. Introdução; 2. Desigualdade e crescimento econômico; 3. Dados e metodologia; \\ 4. Apresentação dos resultados; 5 . Conclusão. \\ Palavras-chave: Desigualdade, Crescimento, System-GMM, Painel Dinâmico. \\ Códigos JEL: $\quad$ C33, E24, E62.
}

\begin{abstract}
Esta pesquisa buscou identificar o efeito da desigualdade no crescimento no Brasil, de forma a mitigar o problema de comparabilidade presente nas pesquisas cross-country. O método econométrico System-GMM foi comparado às estimativas obtidas em um painel dinâmico a partir de outras três técnicas econométricas (MQO, Efeitos-Fixos e GMM), com vistas à obtenção de um estimador consistente frente à endogeneidade existente na relação entre crescimento e desigualdade. Os resultados obtidos sugerem que não se pode rejeitar as hipóteses de não-linearidade entre desigualdade e crescimento, de incompletude dos mercados de crédito e o argumento de que políticas redistributivas mitigam o crescimento.
\end{abstract}

This study attempts to identify the effect of inequality on growth by using Brazilian data, in order to mitigate comparability problems present in cross-country studies. The econometric method System-GMM was used and compared with other three econometric methods (OLS, Panel Within-Groups, and GMM) in a dynamic panel, aiming to use a consistent estimator in the presence of endogeneity in the analysis that involves inequality and growth. Our results suggest that the hypothesis of nonlinearity between the variables cannot be rejected. The same conclusion holds for hypothesis of incomplete credit markets and the argument from political economy that redistributive policies mitigate growth.

\section{INTRODUÇÃO}

Durante os últimos anos pesquisadores têm apresentado conclusões conflitantes acerca da relação entre distribuição de renda e crescimento econômico. Enquanto trabalhos incluindo Forbes (2000) argumentam que a desigualdade exerce efeito positivo no crescimento, outros estudos incluindo Panizza (2002) sugerem que tal impacto é negativo. Grande parte dessas pesquisas, entretanto, se baseia em

\footnotetext{
*Fucape Business School. Av. Fernando Ferrari, 1358, Boa Vista, Vitória-ES, CEP 29075-505. Agradeço o suporte financeiro do da Fundação de Amparo à Pesquisa e Inovação do Espírito Santo (FAPES). E-mail: polianobc@yahoo.com.br

${ }^{\dagger}$ Fucape Business School. Av. Fernando Ferrari, 1358, Boa Vista, Vitória-ES, CEP 29075-505. Agradeço o suporte financeiro do Conselho Nacional de Desenvolvimento Científico e Tecnológico (CNPq). E-mail: arilton@fucape .br

${ }^{\ddagger}$ Fucape Business School. Av. Fernando Ferrari, 1358, Boa Vista, Vitória-ES, CEP 29075-505. E-mail: danilo@fucape.br
} 
análises cross-country e são influenciadas por problemas relacionados à qualidade, consistência e comparabilidade dos dados. Isso se deve principalmente à composição das séries históricas de desigualdade utilizadas, que são construídas por cada agência nacional de estatística com base em metodologias distintas (Knowles, 2005). Análises baseadas em dados de um único país e obtidos a partir de uma mesma pesquisa domiciliar, entretanto, podem ser utilizadas para que sejam obtidos resultados mais robustos e que mitiguem problemas de comparabilidade. Isso decorre da maior homogeneidade dos questionários aplicados, definições adotadas e do contexto cultural e institucional (Sierminska, Brandolini \& Smeeding, 2006).

De acordo com a BBC Brasil (2011), o Brasil foi o único país no grupo dos BRICS a reduzir o abismo entre ricos e pobres em 15 anos e de forma a conciliar crescimento econômico com progresso social. Segundo pesquisa da Oxfam, o Brasil é ainda um dos países com maior eficácia na redução da desigualdade, com a saída de 12 milhões de brasileiros da pobreza absoluta entre 1999 e 2009 e com uma redução no coeficiente de Gini de 0,52 para 0,47 (BBC Brasil, 2012). Nesse sentido, o Brasil torna-se um interessante case de estudo, ao oferecer dados e condições propícias para que a relação entre crescimento econômico e desigualdade possa ser empiricamente verificada, e de forma que sejam mitigados ainda os problemas existentes nos estudos cross-country. Dessa forma, esta pesquisa buscou identificar empiricamente o efeito da desigualdade no crescimento econômico considerando-se o case brasileiro.

Um estudo realizado por Pinto (2012, CPS/FGV) indica que "a diminuição da desigualdade [...] na última década no Brasil se assemelha ao movimento verificado no conjunto de todos os países." O estudo aponta que "a comparação dos índices [de Gini] mostra que o Brasil é uma maquete muito próxima do mundo". Ainda segundo o Pinto (2012), a redução na desigualdade no país é "três vezes superior à meta do milênio da ONU [e] a renda média per capita cresceu 2,7\% desde 2002. Nota-se, na Figura 1, que as inclinações da evolução do Gini, Mundial e do Brasil, são similares e com tendência negativa.

Tais fatos reforçam o Brasil como um case importante no estudo da relação entre desigualdade e crescimento. Algumas declarações, como a do Vice-Governador Sênior do Banco Central do Canada, Tiff Macklem, que "elogiou o Brasil por mostrar ao mundo como aumentar o crescimento econômico, mas ao mesmo tempo reduzir a desigualdade entre ricos e pobres" (Tower, 2012), e do ganhador do prêmio Nobel de economia Amartya Sen de que "o Brasil é um bom exemplo de conciliação entre rápido crescimento econômico e desenvolvimento social [podendo ser] modelo para China e índia" (Fleck, 2012), também realçam tal importância.

Para que fosse possível identificar empiricamente o efeito da desigualdade no crescimento econômico, foi proposto um modelo que procurou incorporar variáveis de controle de forma a mitigar o problema

Figura 1. Evolução do Gini de Renda de 1976 a 2009.

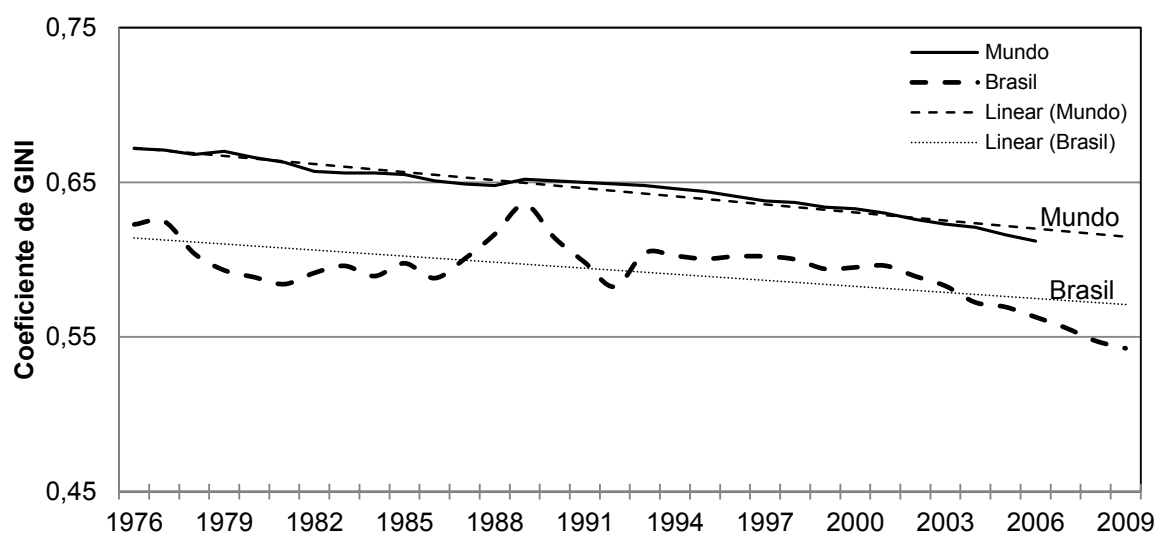

Fonte: IPEADATA; Pinkovskiy e Sala-i-Martin (2009). 
de endogeneidade causado pela omissão de variáveis relevantes, correlacionadas com desigualdade e que afetam o crescimento. O método econométrico System-GMM foi empregado ao modelo proposto e comparado às estimativas obtidas em um painel dinâmico a partir de outras três técnicas econométricas (MQO, Efeitos-Fixos e GMM), com vistas à obtenção de um estimador consistente frente à endogeneidade existente nas análises que envolvem crescimento e desigualdade. Os dados utilizados se referem às vinte e sete Unidades Federativas do Brasil no período entre 1995 a 2009 e foram obtidos junto às bases de dados do IPEADATA, IBGE, PNUD, PNAD/IBGE, SCN/IBGE, SIM-DATASUS, MDIC e STN.

A partir da abordagem que sugere que a desigualdade afeta positivamente o crescimento para níveis mais baixos do PIB per capita, e negativamente quando esse assume valor mais elevado (Barro, 2000, 2008), verificou-se ainda a existência do efeito não linear da desigualdade no crescimento. Os resultados obtidos sugerem que não se pode rejeitar a premissa de não-linearidade entre desigualdade e crescimento, a hipótese da incompletude dos mercados de crédito e o argumento da economia política de que políticas redistributivas mitigam o crescimento.

Este trabalho contribui para a literatura de desigualdade e crescimento ao apresentar evidências de que a desigualdade exerce efeito positivo no crescimento para níveis de PIB per capita mais elevados e efeito negativo para níveis de PIB per capita baixo, o que confirma o questionamento feito por de Dominicis, Florax e de Groot (2008) à concepção teórica proposta por Bénabou (2000) e Galor (2010) de que o efeito da desigualdade no crescimento possui formato de U-invertido. Ao não rejeitar-se a hipótese de incompletude dos mercados de crédito, verifica-se ainda que, diante dos investimentos restritos na educação, a parcela de indivíduos sem a qualificação mínima requerida pelo mercado mitiga as taxas de crescimento do PIB per capita. Esse resultado sugere que o redirecionamento de recursos por parte do indivíduo afim de aumentar-se o nível de educação é fator que pode contribuir para o aumento do PIB per capita.

Os resultados encontrados contribuem ainda para a teoria de economia política ao sugerir que a pressão exercida pela sociedade por mais políticas redistributivas, como forma de atenuar os efeitos da distinção de renda, implicam em um impacto negativo na taxa de crescimento. Tal associação contraria a concepção de que a política redistributiva brasileira é a característica distintiva que permite ao país crescer e reduzir desigualdade concomitantemente. Os resultados sugerem que essa dinâmica pode advir do fato de que a desigualdade exerce efeito negativo no crescimento para níveis de baixo PIB per capita.

Os resultados obtidos contribuem ainda para a literatura de desigualdade e crescimento ao apresentar evidências de que análises in-contry podem mitigar problemas de comparabilidade, tais como os apontados por Atkinson e Brandolini (2009) e Banerjee e Duflo (2003). Os resultados obtidos a partir da comparação das estimações por meio de quatro métodos econométricos também contribuem para a análise empírica da relação entre desigualdade e crescimento ao apresentar considerações acerca de cada um dos estimadores utilizados. Acompanhando metodologia proposta por Bond, Hoeffler e Temple (2001), ao analisar-se os coeficientes do termo auto-regressivo, o método MQO em Painel com AR(1) apresentou viés para cima (Hsiao, 2003; Nerlove, 1967; Trognon, 1978), enquanto a técnica dos Efeitos-Fixos mostrou-se enviesada para baixo (Anderson \& Hsiao, 1982; Nerlove, 1971; Nickell, 1981). O estimador GMM em Primeira Diferença, devido à fraca instrumentalização, apresentou resultados próximos à estimação de Efeitos-Fixos. Comparativamente, a estimação por System-GMM foi a que apresentou melhores resultados, ao produzir coeficientes consistentes e que satisfazem ao Teste de Sargan de sobre-identificação.

O presente artigo segue estruturado da seguinte forma: próxima seção é feita uma revisão das principais questões que envolvem a relação entre desigualdade e crescimento, de forma que seja fornecida sustentação teórica que fundamente a construção do modelo empírico proposto. A seção 3 apresenta uma descrição dos dados, bem como dos procedimentos metodológicos referentes a cada um dos modelos econométricos utilizados. Na seção 4 são apresentados os principais resultados. A seção 5 se destina à conclusão e demais comentários. 


\section{DESIGUALDADE E CRESCIMENTO ECONÔMICO}

No final da década de 40 até início de 50 , os trabalhos que abordavam desigualdade tinham como escopo compreender os efeitos da industrialização no crescimento. Considerava-se que a distribuição de renda derivava do processo de industrialização. Já nos anos 80 , os modelos de crescimento endógeno não consideravam a desigualdade como um dos determinantes do crescimento. Contudo, nos anos 90 , as novas teorias do crescimento e a abordagem da economia política atribuíram à desigualdade papel fundamental no processo de crescimento, renovando o interesse no tema. A disponibilidade de novos dados cross-country permitiu uma série de novos estudos (Ehrhart, 2009). No entanto, as primeiras pesquisas da década de 90 possuíam problemas de variável omitida (Clarke, 1995), não eram robustas a inclusões de dummies regionais (Nancy, Ross \& Sabot, 1995), apresentavam erros de mensuração (Atkinson \& Brandolini, 2009) e não consideravam efeitos específicos não observáveis dos países (Brock \& Durlauf, 2001). Mesmo diante das críticas, Aghion, Caroli e Garcia-Penalosa (1999) ressaltam que esses trabalhos questionaram a visão dominante de que a desigualdade seria benéfica ao crescimento.

\subsection{Efeito positivo da desigualdade no crescimento}

Aghion et al. (1999) destacam que a abordagem que admite efeito positivo da desigualdade no crescimento fundamenta-se, usualmente, em três argumentos: Hipótese de Kaldor, custos indivisíveis de investimentos e trade-off entre eficiência e equidade.

\subsubsection{A hipótese de Kaldor}

A hipótese de Kaldor $(1955-1956,1957)$ diz que a propensão a poupar dos indivíduos ricos é superior à dos indivíduos pobres, sendo a taxa de poupança uma função crescente da renda. Desse modo a desigualdade eleva a taxa de poupança agregada por concentrar renda nos agentes com maior propensão a poupar. Admitindo-se correlação positiva entre poupança e investimento, tem-se que a desigualdade eleva o nível de investimento em capital físico e humano (Galor, 2010; Li \& Zou, 1998). Attanasio e Binelli (2004) destacam que a função poupança deve apresentar monotonicidade para que tal hipótese seja validada. Contudo, a função pode possuir formato de U-invertido. Logo, a desigualdade exerceria efeito positivo no crescimento apenas diante de renda agregada acintosamente baixa, sendo a concentração de renda condição suficiente para estabelecer-se algum grau de acumulação de capital.

\subsubsection{Custos indivisíveis de investimentos}

Assumindo que determinados projetos possuam um custo mínimo elevado, devido principalmente às escalas produtivas necessárias a sua realização, somente indivíduos com alta renda poderiam empreendêlos, pois a alta renda atenua as restrições ao crédito, as quais tornam os custos de se investir elevados. Tal processo tende a ter maior magnitude nos países em desenvolvimento, pois nações desenvolvidas costumam possuir mercados de capitais e instituições legais melhor estruturadas, o que minimiza os efeitos do crédito restrito (Barro, 2000). O estabelecimento e disseminação de novas atividades industriais tem a concentração de renda como condição necessária, pois permitem que haja investidores capazes de incorrer nos custos de implementação, aspecto que pode ser observado nas atividades com alto grau de inovação. Desse modo, alta equidade pode inviabilizar novas atividades econômicas, implicando em perda de eficiência produtiva e mitigando as taxas de crescimento (Aghion et al., 1999).

\subsubsection{Trade-off entre eficiência e equidade}

Mirrlees (1971) defende a existência de um trade-off entre eficiência e equidade. Em sociedades equânimes os agentes econômicos não teriam os incentivos necessários para aumentar seus esforços produtivos. Isso decorre da baixa possibilidade de elevar a renda individual relativa. Como a produção depende desses esforços, que não são passíveis de controle e observação, cria-se um problema de moral hazard. 
Desse modo, equidade elevada pode desestimular os esforços produtivos individuais. Isso implica em perda de eficiência produtiva, o que prejudica o crescimento (Attanasio \& Binelli, 2004).

\subsection{Efeito negativo da desigualdade no crescimento}

$\mathrm{O}$ argumento teórico utilizado pelos estudos que defendem efeito negativo da desigualdade no crescimento é o de que a distribuição de renda influencia os níveis de investimento em capital humano (e.g. qualificação) e físico (e.g. novos empreendimentos) da economia. Os modelos teóricos podem ser divididos em quatro abordagens distintas: Mercado de crédito imperfeito; Economia política; Instabilidade social; Fertilidade e desigualdade.

\subsubsection{Imperfeições do mercado de crédito e seguros}

Baseados no trabalho seminal de Loury (1981), dois fatores são elencados como ocasionadores de imperfeições de mercado, o moral hazard (Piketty, 1997) e o inadimplemento dos pagamentos dos empréstimos (Ehrhart, 2009). O moral hazard ocorre quando a maior parte de um projeto é financiada. 0 mutuário não emprega o máximo de seus esforços produtivos, dado o baixo risco em caso de insucesso (Piketty, 1997). Visando equacionar o risco, os credores elevam as taxas de juros à medida que a participação do financiamento no custo total cresce e estabelecem um percentual máximo de participação dos empréstimos no montante total do investimento, condicionando-os a um nível mínimo de renda. $\mathrm{O}$ indivíduo de baixa renda é, então, impedido de ingressar nas atividades mais produtivas, por não possuir renda suficiente, o que subutiliza o seu potencial produtivo (Ehrhart, 2009). $O$ inadimplemento ocorre quando o percentual de financiamento eleva-se aumentando o risco de moratória. Isso implica em aumento dos custos de transação para garantir os pagamentos e elaborar e fiscalizar os contratos. Dessa forma, os padrões dos investimentos realizados ficam distorcidos, pois dependem diretamente da renda e ativos dos indivíduos. Isso faz com que o crédito se torne restrito, uma vez que os investimentos em capital humano não possuem a liquidez necessária para servir como colateral. Decorrente disso, os investimentos não destinam-se aos projetos mais rentáveis e sim aos mais seguros (Carneiro \& Heckman, 2002).

\subsubsection{Economia política}

A abordagem da economia política fundamenta-se no Teorema do Eleitor Mediano, que traça um paralelo entre o processo eleitoral e o funcionamento do mercado. A ideia central é a de que propostas políticas tendem a ser quase homogêneas devido ao interesse comum dos candidatos em angariar os votos da maioria. Black (1948) consolidou os estudos seminais em seu trabalho sobre votação majoritária ao sugerir que o voto implica em tomada de decisões políticas e econômicas nas quais o nível de renda inicial do eleitor mediano relativo à renda média define suas preferências, de forma a determinar o nível da tributação (Black, 1948) e influenciar a taxa de crescimento futura (Ehrhart, 2009). Como cada voto possui peso igual, elevados níveis de desigualdade (média da renda é superior à renda mediana) implicam em maior demanda por redistribuição, usualmente financiada por tributação, ocasionando distorções econômicas. Os desestímulos causados ao investimento privado, trabalho e poupança resultam em queda nas taxas de crescimento (Alesina \& Rodrik, 1994; Persson \& Tabellini, 1994).

\subsubsection{Instabilidade social}

Para Gupta (1990) a instabilidade social ocorre de três maneiras distintas: por meio de ações diretas de violência contra o governo (e.g. protestos em massa), atos de violência praticados pelo governo (e.g. ações de repressão a distúrbios sociais) e através da violência ocasionada pela mudança de governo (e.g. golpes políticos). Keefer e Knack (2002) apontam a desigualdade como um dos determinantes da instabilidade social, por reduzir os custos de ingresso em atividades ilegais, o que resulta na violação da 
propriedade privada e o desrespeito aos contratos. O ambiente instável abala a credibilidade das instituições e do sistema legal, conduzindo a economia a um nível de investimentos abaixo do ponto ótimo (Perotti, 1996). A baixa estabilidade aumenta os custos de oportunidade, públicos e privados, devido à alta violência, o que eleva gastos com saúde e segurança e o custo de vida geral. Nesse caso, recursos produtivos são em geral desviados para atenuar os efeitos da instabilidade (Alesina \& Perotti, 1996).

\subsubsection{Fertilidade e desigualdade de renda}

Tradicionalmente, na literatura econômica, considera-se que altas taxas de fertilidade exercem impacto negativo no crescimento, e investimentos em educação exercem efeito positivo (Lucas, 2002). Perotti (1996) argumenta que a desigualdade de renda possui correlação positiva com a taxa de fertilidade. As famílias de baixa renda tendem a aumentar a quantidade de filhos como alternativa para elevar a renda familiar, dada a incapacidade em investir-se em educação. As famílias mais abastadas comportamse de maneira inversa, optando por menos filhos, com maior qualificação e saúde, buscando, dessa forma, aumentar a renda por meio da acumulação de capital humano (Ehrhart, 2009).

\subsection{Efeito não-linear da desigualdade no crescimento}

Bénabou (2000) propôs um modelo com incompletude no mercado de crédito, no qual a desigualdade gera concomitantemente perda e ganho de eficiência econômica. A perda decorre da redução dos investimentos em capital humano (indivíduos de alta renda), devido aos desestímulos gerados pela tributação. O ganho advém do incremento nos investimentos em educação (indivíduos de baixa renda), dada a atenuação da restrição ao crédito (Ehrhart, 2009). Galor (2010) propõe a unificação da visão fundamentada na hipótese de Kaldor com a abordagem dos mercados de crédito imperfeitos. $O$ efeito da desigualdade no crescimento dependeria do PIB per capita, sendo a acumulação de capital, físico e humano, o motor do crescimento. Para níveis baixos do PIB, o capital físico é o principal determinante do crescimento, verificando-se a hipótese de Kaldor, com o aumento da poupança suplantando o efeito negativo da desigualdade no acumulo de capital humano, dado o crédito restrito. Já em níveis elevados do PIB, o capital humano torna-se a principal engrenagem do crescimento e os malefícios ocasionados pela restrição de crédito tornam-se superiores aos benefícios propiciados pela acumulação de capital físico (Galor, 2010).

\subsection{Evidências empíricas}

\subsubsection{Efeito negativo da desigualdade no crescimento}

Fishlow (1996) arguiu que a forte correlação negativa entre desigualdade e crescimento encontrada nos estudos da década de 90 advém de variável omitida (relacionada à educação) e do fato de não considerar-se as características regionais dos países. Corrigindo para estas variáveis omitidas, Deininger e Squire $(1996,1998)$ (incluindo dummies regionais) e Alesina e Rodrik (1994) (controlando os níveis de escolaridade primária e PIB per capita) encontraram efeito negativo da desigualdade no crescimento.

Entretanto, os autores acima utilizaram o Gini para medir a desigualdade de distribuição de terras como proxy para controlar a desigualdade de distribuição de riqueza. No entanto, para Griffin e Ickowitz (1997), variáveis de concentração de terras são inadequadas, pois consideram-se apenas a renda dos donos de terras, a posse da terra (distribuída, quase sempre, de forma mais equânime) e cada fazenda como uma unidade de propriedade individual.

Knowles (2005) ressalta que o comportamento e os padrões da distribuição de renda, famílias, indivíduos e o sistema de tributação costumam ser distintos entre os países. Visando minimizar problemas de heterogeneidade nas análises cross-country, Deininger e Squire (1996) e Perotti (1996) propuseram transformações nos dados de "alta qualidade" brutos. No entanto, mesmo com melhora, admitiu-se que a relação entre as várias categorias de renda e despesas fosse constante entre os países e ao longo do tempo (Knowles, 2005). Panizza (2002), ao analisar por painel os 48 estados norte-americanos utilizando o estimador GMM, evidenciou efeito negativo. Contudo, a adoção de métricas distintas de desigualdade 
Figura 2. Canais Pelos Quais a Desigualdade Pode Afetar o Crescimento.

Efeito Positivo da Desigualdade no Crescimento

Bourguignon (1981); Kaldor (1955-1956, 1957); Keynes (1920).

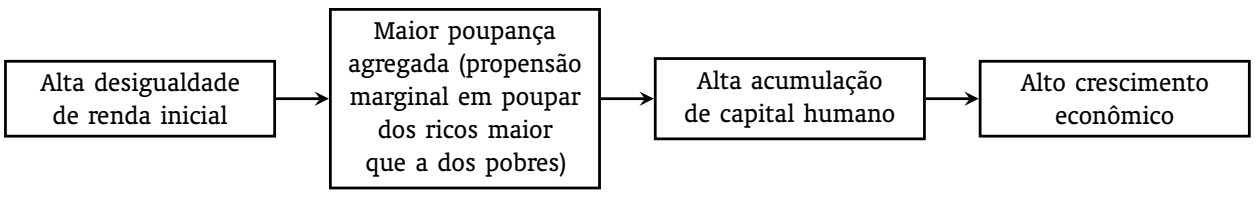

Efeito Negativo da Desigualdade no Crescimento

Alesina e Perotti (1996); Alesina e Rodrik (1994); Keefer e Knack (2002); Persson e Tabellini (1994).

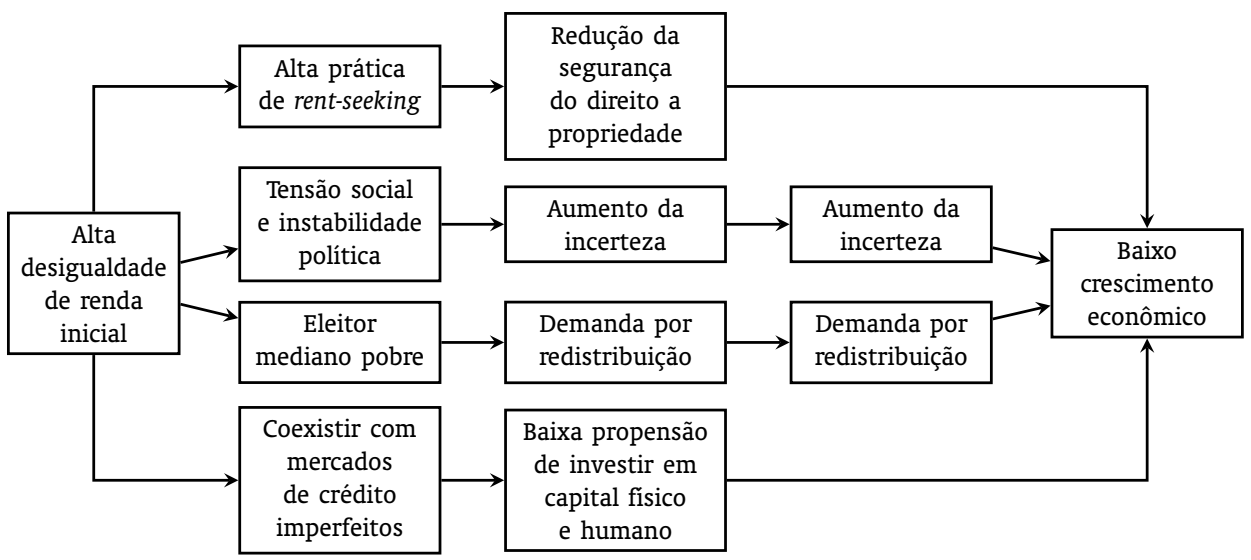

\section{A Abordagem Unificada}

Galor (2010)

Estágio inicial com baixo PIB per capita

Mercado de crédito amplamente vinculativo. Acumulação de capital físico é a principal engrenagem do crescimento.

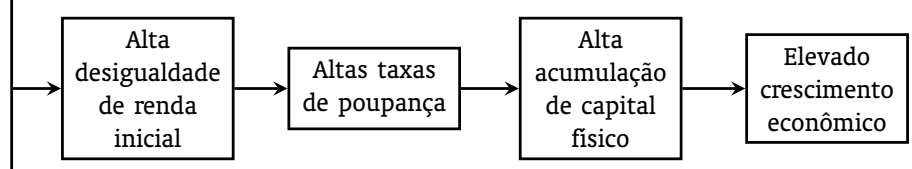

\begin{tabular}{|c|}
\hline Estágio inicial com \\
baixo PIB per capita \\
Restrição de crédito \\
menos vinculativa. \\
Acumulação de capital \\
humano é a principal en- \\
grenagem do crescimento.
\end{tabular}

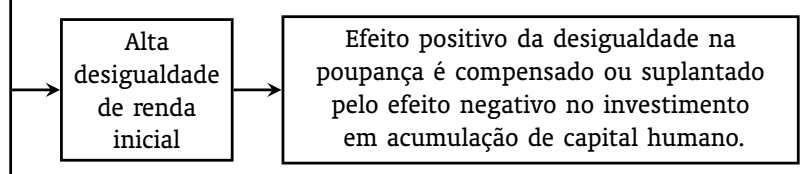

Fonte: Adaptado de Iradian (2005, p.5). 
resultou em variabilidade contundente no efeito da desigualdade no crescimento. Diante disso, Panizza (2002) afirma que não se pôde confirmar que o efeito da desigualdade seja necessariamente negativo.

\subsubsection{Efeito positivo da desigualdade no crescimento}

Li e Zou (1998) sugeriram que a premissa de que o efeito da desigualdade no crescimento é negativo deveria ser revista, pois os resultados obtidos em sua análise em painel, na qual controlou-se os efeitos não observáveis dos países, se contrapuseram as evidências encontradas nos anos 90. Forbes (2000) argui que o viés desses estudos decorre de endogeneidade advinda de variável omitida. Pelo estimador GMM, controlando-se por escolaridade, PIB e investimentos, e utilizando-se Efeitos-Fixos com dummies temporais (controle de choques econômicos) e regionais (controle de variável omitida), Forbes (2000) evidenciou efeito positivo da desigualdade.

Aghion et al. (1999, pp.1618-1619) ressaltam três problemas no trabalho de Forbes (2000). Primeiro, o estimador "GMM utilizado resulta em erros padrão excessivamente pequenos quando a amostra é pequena, levando-se a questionar a significância dos coeficientes". Segundo, o uso incorreto de defasagem nos regressores, pois como padrão admite-se que a desigualdade exerça efeito ao longo de cinco anos no crescimento. E por fim, a exclusão da amostra de países, dos quais não se obtiveram dados de "alta qualidade”. Roodman (2009) ressalta, ainda, que o uso excessivo de instrumentos relativo ao número de observações pode ter ocasionado problema de over-fitting, não se expurgando, assim, a endogeneidade e aproximando a estimação da obtida por MQO.

\subsection{Efeito não-linear da desigualdade no crescimento}

Utilizando dados de "alta qualidade" e separando a amostra em países desenvolvidos e em desenvolvimento, Barro (2000) evidenciou efeito não-linear, com impacto positivo da desigualdade no crescimento dos países desenvolvidos e negativo nos demais. Banerjee e Duflo (2003) apontam a não-linearidade como o motivo das divergências empíricas entre os estudos, que admitem, em sua maioria, causalidade linear. Ao realizarem regressões replicando as técnicas de estimação utilizadas nas principais pesquisas feitas, tais autores concluíram não haver evidências de que a técnica de Efeitos-Fixos tenha expurgado o viés da endogeneidade. Assim, a forma mais eficiente de identificar o efeito da desigualdade no crescimento seria conceber não-linearidade na estimação. Gregorio e Lee (2004) e Fielding e Torres (2006) arguem que a desigualdade exerce efeito indireto no crescimento, por possuir correlação com outras variáveis que também o afetam. Barro (2008) investigou possíveis efeitos indiretos, analisando a interação da desigualdade com a fertilidade (efeito positivo), democracia (efeito negativo) e ensino secundário (efeito negativo). Os resultados da interação das variáveis com o Gini não obtiveram significância estatística ou resultaram em coeficientes muito pequenos, sendo desse modo, suplantados pelo efeito direto da desigualdade no crescimento (Barro, 2008).

\subsubsection{A influência do método econométrico e composição da amostra}

Voitchovsky (2005, p.290) argumenta que há um padrão nos resultados encontrados na literatura, no qual "o efeito da desigualdade no crescimento é sensível à técnica econométrica utilizada". A autora argui que técnicas que valem-se mais da "variação das séries temporais nos dados tendem a indicar efeito positivo da desigualdade no crescimento (e.g. Forbes, 2000)". Já métodos que utilizam mais os dados cross-section "tendem a indicar efeito negativo (e.g. Alesina \& Rodrik, 1994)". Para de Dominicis et al. (2008, p.670) as divergências empíricas encontradas (Barro, 2000, 2008; Bénabou, 2000; Forbes, 2000; Knowles, 2005; Perotti, 1996) podem ser atribuídas "às diferenças nos tipos de dados utilizados, do método de estimativa, qualidade dos dados, o período de tempo considerado, e cobertura da amostra". Deininger e Okidi (2003) e Bourguignon (2004) defendem que estudos em um único país (Deininger \& Okidi, 2003; Panizza, 2002) obtêm resultados mais robustos, devido ao maior controle das variáveis não observáveis oriundas de características distintivas dos países. 
No entanto, a maioria dos trabalhos empíricos sobre desigualdade e crescimento utiliza dados crosscountry, ao invés de microdados de um único país (Otter, 2009). Grande parte dessas pesquisas tem sofrido críticas acerca da qualidade, consistência e comparabilidade dos dados utilizados, principalmente em relação às séries históricas de desigualdade (Schipper \& Hoogeveen, 2005; Sierminska et al., 2006). Atkinson e Brandolini (2009) e Banerjee e Duflo (2003) destacam que as agências nacionais de estatística responsáveis pela compilação dos dados utilizam metodologias distintas, o que dificulta a comparabilidade. Devido à esses fatores, as pesquisas cross-country combinam de forma inconsistente dados heterogêneos não comparáveis. Tal procedimento é inadequado, uma vez que o comportamento da distribuição de renda e os padrões de distribuição de famílias e indivíduos variam entre os países (Ehrhart, 2009; Knowles, 2005). Ao combinar dados de diversos países, os estudos assumem a hipótese de constância nos parâmetros estimados, desconsiderando-se os efeitos dos fatores específicos dos países, quase sempre advindos de variáveis não observáveis. Dessa forma, as inferências causais nesses estudos carecem de poder explicativo (Brock \& Durlauf, 2001; Deininger \& Okidi, 2003).

Estudos feitos em um único país com dados provenientes de uma mesma pesquisa domiciliar têm os problemas de comparabilidade atenuados, dado que os questionários aplicados, as definições adotadas, os contextos cultural e institucional, dentre outras questões, são mais homogêneos (Deininger \& Okidi, 2003; Otter, 2009; Sierminska et al., 2006). Para Bourguignon (2004), os estudos cross-country que investigaram crescimento e desigualdade e não obtiveram significância estatística em seus resultados não rejeitam a hipótese de existência de correlação ou causalidade entre as variáveis. Tais estudos apenas reforçam o fato de que as especificidades dos países são cruciais na forma como tais fenômenos interagem. Dessa forma torna-se quase inviável que se façam generalizações aplicáveis a todas as nações (Bourguignon, 2004).

\section{DADOS E METODOLOGIA}

A amostra é composta por dados secundários das 27 Unidades Federativas brasileiras, compreendendo o período entre 1995 a 2009. As informações tiveram como fonte as bases de dados do IPEADATA, IBGE, PNUD, PNAD/IBGE, SCN/IBGE, SIM-DATASUS, MDIC, STN. Os valores monetários estão em Reais constantes (ano-base 2000), deflacionados pelo Deflator de Transformação do PIB Implícito do IPEA. Os valores foram transformados em Logaritmo Neperiano ou em Taxas (e.g. Receitas Públicas/PIB).

\subsection{Procedimentos metodológicos}

Os estudos de desigualdade e crescimento da década de 90 adotaram o método de regressão crosscountry com equação reduzida, no qual combina-se uma medida de desigualdade a um conjunto de variáveis explanatórias (de Dominicis et al., 2008). Os resultados, na maioria, indicam correlação negativa robusta entre as variáveis, assumindo, usualmente, uma relação linear do tipo

$$
\left(\ln y_{i, t}-\ln y_{i, t-\tau}\right) \frac{1}{\tau}=\alpha_{0} \ln y_{i, t-\tau}+\alpha_{1} g_{i, t-\tau}+\beta X_{i, t-\tau}+\varepsilon_{i, t},
$$

onde $\left(\ln y_{i, t}-\ln y_{i, t-\tau}\right) \frac{1}{\tau}$ é a média anual da taxa de crescimento do PIB per capita real do país $i$ no tempo $t ; \tau$ o intervalo de tempo; $g_{i, t-\tau}$ a medida de desigualdade; $X_{i, t-\tau}$ a matriz de variáveis de controle incluindo uma constante; e $\varepsilon_{i, t}$ o termo de erro.

A principal crítica a esse tipo de abordagem é a possibilidade de existência de viés devido a variáveis não observáveis específicas de cada país (e.g. padrões tecnológicos, estabilidade das instituições e diferenças culturais, climáticas) que podem explicar o crescimento econômico. Buscando controlar por tais fatores, pesquisas em painel admitem que essas variáveis sejam constantes no tempo e utilizam mais séries temporais que dados em cross-section (de Dominicis et al., 2008). Controlam-se, então, as características não observáveis por meio de Efeitos-Fixos ou Aleatórios, resultando em uma equação do tipo

$$
\Delta \ln y_{i, t}=\bar{\propto}_{0} \Delta \ln y_{i, t-\tau}+\bar{\propto}_{1} g_{i, t-\tau}+\bar{\beta} X_{i, t-\tau}+\aleph_{t}+v_{i}+\bar{\varepsilon}_{i, t},
$$


onde $\aleph_{t}$ é o termo de Efeitos-Fixos específico no tempo; $v_{i}$ são as características constantes no tempo de cada país; $\bar{\varepsilon}_{i, t}$ capta a parte remanescente do erro variante no tempo e nos países.

Os modelos de Efeitos-Fixos permitem a correlação das variáveis condicionais com os efeitos não observáveis individuais. Essa técnica é utilizada para analisar o efeito de variáveis que afetam o crescimento no longo prazo ou possuam razoável constância ao longo do tempo (Temple, 1999). Contudo, o método ignora efeitos persistentes, podendo resultar em conclusões imprecisas nos casos em que a maior parte da variação advém do corte transversal (e.g. série de desigualdade). Adicional a isso o fato da equação possuir regressores defasados compromete a hipótese de exogeneidade estrita das variáveis explicativas (de Dominicis et al., 2008).

Uma alternativa para tais questões é o estimador GMM. Arellano e Bond (1991) propuseram uma regressão em painel dinâmico, na qual a equação utilizada é diferenciada em primeira ordem, resultando em uma equação livre dos efeitos fixos. Suponha, sem perda de generalidade, um modelo auto-regressivo:

$$
\begin{aligned}
y_{i, t}=\beta y_{i, t-1}+n_{i}+v_{i, t} \\
\text { para } \quad \text { i) }|\beta|<1 \\
\text { ii) } i=1, \ldots, N \\
\text { iii) } t=2, \ldots, T,
\end{aligned}
$$

onde $y_{i, t}$ é a taxa de Crescimento anual do PIB per capita dos estados $i$ no período $t ; n_{i}$ é um fator específico não observável dos estados; $v_{i, t}$ é o resíduo; e $n_{i}+v_{i, t}=\mu_{i, t}$ é o termo de erro. Suponha ainda que as esperanças condicionais sejam, para $i=1, \ldots, N$ e $t=2, \ldots, T$,

$$
\mathrm{E}\left[n_{i}\right]=0 \quad \mathrm{E}\left[v_{i, t}\right]=0 \quad \mathrm{E}\left[n_{i} v_{i, t}\right]=0,
$$

e onde o termo de erro $v_{i, t}$ não seja serialmente autocorrelacionado:

$$
\mathrm{E}\left[v_{i, t} v_{i, s}\right]=0
$$

para $i=1, \ldots, N$ e $s \neq t$.

Tem-se como condição de início, predeterminada, de $y_{i, 1}$,

$$
\mathrm{E}\left[y_{i, 1} v_{i, t}\right]=0,
$$

para $i=1, \ldots, N$ e $t=3, \ldots, T$.

Dados (3) a (6) a endogeneidade é tratada utilizando os regressores defasados (no mínimo em dois períodos) como variáveis instrumentais de (3) em primeira diferença. Para estimar o parâmetro $\beta$ existem $m=0,5(T-1)(T-2)$ condições de momento suficientes para uma amostra $T$ (Bond et al., 2001):

$$
\mathrm{E}\left[y_{i, t-s} \Delta v_{i, t}\right]=0
$$

para $t=3, \ldots, T$ e $s \geq 2$.

Pode-se escrever (7) matricialmente como

$$
\mathrm{E}\left[\boldsymbol{Z}_{i}^{\prime} \Delta \boldsymbol{v}_{i}\right]=\mathbf{0},
$$

onde $\boldsymbol{Z}_{i}$ é a matriz, de dimensão $(T-2) \times m$,

$$
\boldsymbol{Z}_{i}=\left[\begin{array}{ccccccc}
y_{i, 1} & 0 & 0 & \cdots & 0 & \cdots & 0 \\
0 & y_{i, 1} & y_{i, 2} & \cdots & 0 & \cdots & 0 \\
\vdots & \vdots & \vdots & \ddots & \vdots & \ddots & \vdots \\
0 & 0 & 0 & \cdots & y_{i, 1} & \cdots & y_{i, T-2}
\end{array}\right]
$$


$\mathrm{e}$

$$
\Delta v_{i}=\left(\Delta v_{i, 3}, \Delta v_{i, 4}, \ldots, \Delta v_{i, T}\right)^{\prime}
$$

é um vetor de dimensão $(T-2) \times 1$.

Os ganhos em relação aos outros métodos, ao utilizar-se o GMM, são ausência de viés, oriundos dos efeitos fixos temporalmente invariantes, e consistência do estimador diante de endogeneidade. Isso torna-se possível uma vez que o estimador minimiza a norma de $\Delta v^{\prime} Z W Z^{\prime} \Delta v$, na qual $Z$ é a matriz de instrumentos de dimensão $M \times N(T-2)$ e definida por $\left[\boldsymbol{Z}_{1}^{\prime}, \boldsymbol{Z}_{2}^{\prime}, \ldots, \boldsymbol{Z}_{N}^{\prime}\right]$; $\boldsymbol{W}$ é a matriz de ponderação; $\Delta v$, definida como $\left[\Delta v_{1}^{\prime}, \Delta v_{2}^{\prime}, \ldots, \Delta v_{N}^{\prime}\right]$, é a matriz de erros de dimensão $N(T-2) \times 1$. Nesse caso, utilizar um conjunto apropriado de instrumentos, obter $N$ suficientemente grande e $T$ fixo são condições necessárias para consistência do estimador (Bond et al., 2001). O conjunto de dados dessa pesquisa possui $N=27$ e $T=15$.

No entanto, Blundell e Bond (1998) realizaram uma série de experimentos de Monte Carlo atestando que "o estimador System-GMM possui melhores propriedades de amostra finita, em termos de viés e erro quadrático, do que o estimador GMM" (Bun \& Kleibergen, 2010, p.2). Na presença de variáveis com efeito persistente, os níveis defasados da série temporal constituem uma instrumentalização fraca após a primeira diferença quando $T$ é pequeno. Isso ocorre quando algumas variáveis são associadas a tamanho (e.g. dependentes da população ou da renda agregada) ou na presença de termos dinâmicos. $O$ fato dos instrumentos possuírem fraca correlação com a equação em primeira diferença ocasiona problema de correlação espúria, e a defasagem indica, de maneira errônea, a existência de uma raiz unitária (Bond et al., 2001).

Arellano e Bover (1995) e Blundell e Bond (1998) propõem uma condição de momento adicional ao GMM:

$$
\mathrm{E}\left[n_{i} \Delta y_{i, 2}\right]=0
$$

para $i=1, \ldots, N$.

É condição suficiente para que se garanta (11) que a média de $y_{i, t}$ seja constante $\forall i, t$. No entanto, essa condição de estacionaridade só se faz necessária nos primeiros momentos de $y_{i, t}$. Mesmo diante da correlação entre $\Delta y_{i, t}$ e $n_{i}$, por hipótese ela assume o valor zero. Admitindo (3) a (6) e (11) adiciona-se $T-2$ condições de momentos, como vê-se em (12):

$$
\mathrm{E}\left[\mu_{i, t} \Delta y_{i, t-1}\right]=0 \text {, }
$$

para $i=1, \ldots, N$ e $t=3,4, \ldots, T$.

Assim, por um sistema de equações, o System-GMM, "combina condições de momento para o modelo em primeira diferença com condições de momento para o modelo em nível". Os níveis defasados são os instrumentos das primeiras diferenças e as primeiras diferenças defasadas instrumentalizam a equação em nível (Bun \& Kleibergen, 2010, p.2), onde pelo uso de (7) e (12) origina a matriz de instrumentos (13):

$$
\boldsymbol{Z}_{i}^{+}=\left[\begin{array}{ccccc}
\boldsymbol{Z}_{i} & 0 & 0 & \cdots & 0 \\
0 & \Delta y_{i, 2} & 0 & \cdots & 0 \\
0 & 0 & \Delta y_{i, 3} & \cdots & 0 \\
\vdots & \vdots & \vdots & \ddots & \vdots \\
0 & 0 & 0 & \cdots & \Delta y_{i, T-1}
\end{array}\right],
$$

onde de (9) obtem-se $\boldsymbol{Z}_{i}$.

Reescrevendo essa nova condição de momento em forma matricial tem-se

$$
\mathrm{E}\left[\boldsymbol{Z}_{i}^{+\prime} \boldsymbol{\mu}_{i}^{+}\right]=0
$$

onde $\mu_{i}^{+}=\left(\Delta v_{i, 3}, \ldots, \Delta v_{i, T}, v_{i, 3}, \ldots, v_{i, T}\right)^{\prime}$. 
Na presença de séries persistentes, as primeiras diferenças defasadas mostram-se instrumentos mais eficientes para os níveis. Dada às propriedades de amostra finita, dado a validez dos instrumentos o System-GMM é um estimador consistente (Bond et al., 2001).

\subsubsection{Especificações do modelo}

Essa pesquisa utilizou variáveis com comportamento tipicamente persistente, como o PIB per capita e Gini de Renda. Como visto no tópico anterior, o System-GMM mostra-se robusto diante dessa característica (Bond et al., 2001). O modelo proposto nesse trabalho é

$$
y_{i, t}=\beta_{1} y_{i, t-1}+\beta_{2} x 1_{i, t}+\beta_{3} x 2_{i, t}+\cdots+\beta_{13} x 12_{i, t}+n_{i}+v_{i, t},
$$

onde $i$ representa os estados e $t$ o período; $y_{i, t}$ é a Taxa de Crescimento anual do PIB per capita; $y_{i, t-1}$ é o Termo dinâmico; $x 1_{i, t}$ é a Variável de Desigualdade; $x 2_{i, t}$ é a Variável de Interação; $x 3_{i, t}$ é a Taxa de Homicídios por 100.000 Habitantes; $x 4_{i, t}$ é a Escolaridade Média; $x 5_{i, t}$ é a Taxa de Analfabetismo; $x 6_{i, t}$ é o Ln da Taxa de Fertilidade; $x 7_{i, t}$ é a Esperança de Vida ao Nascer; $x 8_{i, t}$ é o Grau de Abertura Econômica; $x 9_{i, t}$ é a Razão das Receitas Públicas Estaduais pelo PIB; $x 10_{i, t}$ é a Razão dos Gastos Públicos Estaduais pelo PIB; $x 11_{i, t}$ é a Razão dos Investimentos Públicos Estaduais pelo PIB; $x 12_{i, t}$ é a Razão dos Gastos Públicos Estaduais com Educação pelo PIB; $n_{i}$ é um fator específico não observável; $v_{i, t}$ é o resíduo.

Buscando mitigar o problema apontado por Voitchovsky (2005) de que a técnica econométrica adotada influencia no sinal do efeito da desigualdade no crescimento, restringiu-se a análise a um único país, com vistas a tornar os dados mais homogêneos e controlar possíveis variáveis não-observáveis. Buscouse ainda a construção de um modelo que incluísse variáveis de controle para os principais canais pelos quais a desigualdade pode afetar o crescimento. Visando detectar a presença de viés em amostra finita, Bond et al. (2001, p.7) propuseram uma metodologia na qual comparam-se os resultados obtidos para o termo auto-regressivo pelo estimador GMM com os coeficientes obtidos por estimativas alternativas. Os autores arguem que uma estimação por MQO de (15) "irá resultar em uma estimativa de $\beta_{1}$ enviesada para cima, na presença de efeitos específicos individuais". Nerlove (1967), Trognon (1978) e Hsiao (2003) provaram que, devido às propriedades de amostra finita, em modelos dinâmicos a correlação entre os efeitos específicos e $\beta_{1}$ ocasiona viés assintótico na estimação por MQO, superestimando os resultados. "A inclusão de variáveis exógenas no processo auto-regressivo de primeira ordem não altera a direção do viés do estimador do coeficiente da variável dependente defasada", e identificar o viés assintótico de um processo auto-regressivo de alta ordem mostra-se demasiadamente dificil (Hsiao, 2003, p.73).

Já uma estimação por Efeitos-Fixos "resultaria em uma estimativa de $\beta_{1}$ seriamente enviesada para baixo em painéis" com $T$ pequeno (Bond et al., 2001, p.7). Nerlove (1971), Nickell (1981) e Anderson e Hsiao (1982) provaram que, dada a presença de efeitos individuais, o estimador de covariância em um painel dinâmico é inconsistente quando utilizados Efeitos-Fixos. Quando $T$ é fixo, não importa quão grande seja $N$, o estimador será enviesado, devido à $\mu_{i}$ ser não correlacionado com o efeito individual não observável e ser distribuído de forma idêntica e independente, dado a Lei dos Grandes Números (Rao, 1973). "Isso é ocasionado por ter-se que eliminar o efeito individual não conhecido de cada observação, o que cria uma correlação de ordem $1 / T$ entre as variáveis explanatórias e os resíduos do modelo transformado" (Hsiao, 2003, p.72):

$$
\left(y_{i, t}-\bar{y}_{i}\right)=\beta_{1}\left(y_{i, t-1}-\bar{y}_{i,-1}\right)+\left(\mu_{i, t}+\bar{\mu}_{i}\right) .
$$

No entanto, pode-se estimar $\beta_{1}$ de maneira consistente pelo uso de um estimador assintóticamente não enviesado combinado ao uso de variáveis instrumentais (Hsiao, 2003). Pode-se considerar que $\beta_{1}$ foi estimado de forma consistente quando o valor obtido encontra-se no intervalo entre a estimação por MQO e Efeitos-Fixos. Caso o coeficiente do GMM esteja muito próximo ou abaixo da estimativa de EfeitosFixos "parece provável que a estimação esteja, também, enviesada para baixo, devido aos instrumentos fracos", podendo ser considerado como um indício de que o viés possa ser significante (Bond et al., 2001, 
p.7). Nesses casos, Bond et al. (2001, p.7) sugerem que verifique-se "a qualidade dos instrumentos pelo estudo de equações de forma reduzida, para variáveis dependentes defasadas, diretamente ou considerar estimadores alternativos que possam ter melhores propriedades para amostras finitas diante de séries persistentes". Dado que as estimações de $\beta_{1}$ por MQO e Efeitos-Fixos possuem viés "em direções opostas, então, deixando de lado a variabilidade amostral e considerações de amostra-pequena, uma estimação consistente do parâmetro deve ficar entre esses dois extremos" (Nerlove, 1999). Isso implica que "formalmente, quando as variáveis explanatórias, com exceção de $y_{i, t-1}$, são estritamente exógenas" (Durlauf, 2005, p.663), temos

$$
p \lim \hat{\beta}_{\mathrm{EF}}<p \lim \hat{\beta}<p \lim \hat{\beta}_{\mathrm{MQO}},
$$

onde $\hat{\beta}_{\mathrm{EF}}$ é obtido pela estimação por Efeitos-Fixos; $\hat{\beta}_{\mathrm{MQO}}$ é obtido pela estimação por MQO; $\hat{\beta}$ é parâmetro consistente.

No entanto, a condição (17) pôde ser apenas intuitivamente observada nesse estudo, dado que a endogeneidade dos regressores é tratada por meio de variáveis instrumentais. Contudo, tanto Bond et al. (2001) como Durlauf (2005) defendem que dado que o viés dos estimadores MQO e Efeitos-Fixos possuem direções opostas, é esperado que uma estimação consistente de $\beta_{1}$ encontre-se entre os coeficientes obtidos por esses métodos.

\section{APRESENTAÇÃO DOS RESULTADOS}

Diante da metodologia exposta, o modelo em (15) foi estimado por meio de quatro métodos econométricos distintos, cujos resultados encontram-se nas quatro seções seguintes, com o intuito de identificar qual das técnicas resultaria em um $\beta_{1} \in\left(\beta_{1(\mathrm{EF})}, \beta_{1(\mathrm{MQO})}\right)$ (Bond et al., 2001), o que intuitivamente sugeriria que o $\beta_{1}$ atendeu ao critério exposto em (17) (Durlauf, 2005). Para captar a não-linearidade entre desigualdade e crescimento, adotou-se a metodologia proposta por Barro (2000). Incluiu-se no modelo uma Variável de Interação dada pelo produto do Ln do PIB per capita e a Variável de Desigualdade (e.g. Gini de Renda). "Um coeficiente positivo na Variável de Interação indica que o impacto negativo da desigualdade é maior" para valores baixos de PIB per capita. "Esse efeito atenua-se com o aumento do PIB" até o ponto em que o "efeito estimado da desigualdade torna-se positivo" (Barro, 2008, p.7):

$$
y_{i, t}=\left[\beta_{2} \operatorname{Gini}+\beta_{3}(\operatorname{Gini} \times P I B)\right] .
$$

\subsection{Método dos Mínimos Quadrados (MQO) em Painel}

Por ser considerado o Best Linear Unbiased Estimator (BLUE), estimou-se (15) pelo método MQO com $\mathrm{AR}(1)$. Os valores dos coeficientes da Variável de Desigualdade apresentados na Tabela 1 sugerem efeito negativo da desigualdade no crescimento para baixos valores de PIB per capita. Já os coeficientes com sinal positivo da Variável de Interação sugerem efeito contrário quando tem-se um PIB per capita elevado. Dessa forma, não rejeitou-se a presença de não-linearidade entre desigualdade e crescimento.

Tabela 1. Coeficientes das variáveis de desigualdade (MQO).

\begin{tabular}{lccccc}
\hline \multicolumn{1}{c}{ Variável } & Gini & L-Theil & Pobreza & $\begin{array}{c}\text { Extr. } \\
\text { Pobreza }\end{array}$ & $\frac{10 \% \text { Ricos }}{40 \% \text { Pobres }}$ \\
\hline Desigualdade & $-0,861^{*}$ & $-0,729^{* * *}$ & $-0,009^{* *}$ & 0,002 & \multicolumn{1}{c}{$-0,006^{*}$} \\
Interação & $0,0956^{* * *}$ & $0,081^{* * *}$ & $0,001^{* *}$ & $-0,000008$ & $0,00002^{* *}$ \\
\hline
\end{tabular}

${ }^{* * *} p<0,01 ;{ }^{* *} p<0,05 ;{ }^{*} p<0,1$. 


\subsection{Método MQO com Efeitos-Fixos em Painel (Efeitos-Fixos)}

Buscando minimizar a possível presença de viés na estimação por MQO advinda dos efeitos específicos, estimou-se (15) pelo método dos Efeitos-Fixos. Para tal, admitiu-se que esses efeitos são constantes no tempo e permitiu-se a correlação das variáveis condicionais com os mesmos. Observa-se na Tabela 2 que houve mudança na magnitude dos valores dos coeficientes de desigualdade. Contudo, ainda não rejeita-se o efeito não-linear da desigualdade no crescimento. Isso é observado pelos sinais negativo da Variável de Desigualdade e positivo na Variável de Interação.

Tabela 2. Coeficientes das variáveis de desigualdade (Efeitos-Fixos).

\begin{tabular}{lrrrcc}
\hline Variável & Gini & L-Theil & Pobreza & $\begin{array}{c}\text { Extr. } \\
\text { Pobreza }\end{array}$ & \multicolumn{1}{c}{$\frac{10 \% \text { Ricos }}{40 \% \text { Pobres }}$} \\
\hline Desigualdade & $-3,429^{* * *}$ & $-1,983^{* * *}$ & $-0,021^{* * *}$ & 0,004 & \multicolumn{1}{c}{$-0,007^{*}$} \\
Interação & $0,441^{* * *}$ & $0,241^{* * *}$ & $0,003^{* * *}$ & $-0,0000089$ & $0,00002^{* *}$ \\
\hline${ }^{* * *} p<0,01 ;{ }^{* *} p<0,05 ;{ }^{*} p<0,1$. & & & &
\end{tabular}

\subsection{Método MM em Primeira Diferença (GMM)}

Com vistas a mitigar o possível viés para baixo no estimador de Efeitos-Fixos devido à possibilidade do estimador de covariância ser inconsistente, dado o fato da dimensão temporal do painel ser pequena e fixa (15 anos), utilizou-se o método GMM. A equação (15) foi diferenciada em primeira ordem, resultando em uma nova equação livre dos efeitos fixos não observáveis. A endogeneidade presente nas variáveis explanatórias foi tratada pela utilização dos regressores defasados em no mínimo dois períodos como instrumentos da nova equação, conforme sugerido na literatura. Admitiu-se que os erros não são serialmente correlacionados e os regressores foram predeterminados por ao menos um período. Os coeficientes exibidos na Tabela 3 apresentaram mudança na magnitude dos valores comparados ao MQO e Efeitos-Fixos. Novamente a não-linearidade não foi rejeitada.

Tabela 3. Coeficientes das variáveis de desigualdade (GMM).

\begin{tabular}{lrrrcc}
\hline Variável & Gini & L-Theil & Pobreza & $\begin{array}{c}\text { Extr. } \\
\text { Pobreza }\end{array}$ & \multicolumn{1}{c}{$\frac{10 \% \text { Ricos }}{40 \% \text { Pobres }}$} \\
\hline Desigualdade & $-10,756^{* * *}$ & $-7,956^{* * *}$ & $-0,041^{* *}$ & 0,003 & $-0,0144^{* *}$ \\
Interação & $1,343^{* * *}$ & $0,951^{* * *}$ & $0,005^{* *}$ & $-0,000015$ & $0,000038^{* * *}$ \\
\hline
\end{tabular}

${ }^{* * *} p<0,01 ;{ }^{* *} p<0,05 ;{ }^{*} p<0,1$.

\subsection{Generalized Method of Moments System}

Objetivando sanar o problema da fraca instrumentalização no método GMM (Teste de Sargan de sobre-identificação apresentou Valor- $p$ da Estatística $J$ 0,0000), estimou-se (15) por meio do SystemGMM a partir da adição da condição de momento (11) às condições já estabelecidas no GMM. Nas novas regressões de (15) os níveis defasados foram usados como instrumentos para as primeiras diferenças. Já as primeiras diferenças defasadas foram empregadas como instrumentos para a equação em nível. Todos os instrumentos foram defasados em ao menos dois períodos, acompanhando a literatura. O SystemGMM propiciou um menor ranking de instrumentos relativo à estimação por GMM, o que minimiza a 
possibilidade de over-fitting. Nota-se na Tabela 4 que a não-linearidade na relação entre desigualdade e crescimento não foi rejeitada, dados os coeficientes negativos da variável de Desigualdade e positivos na variável de Interação. Os resultados foram significantes estatisticamente quando a desigualdade foi mensurada pelo Gini de Renda, $L$ de Theil e Taxa de Extrema Pobreza. Desse modo, encontraram-se evidências de efeito positivo da desigualdade diante de um PIB per capita elevado e negativo quando o PIB per capita é baixo. Tais resultados são similares aos de Barro $(2000,2008)$ e Voitchovsky $(2005)$.

Tabela 4. Coeficientes das Variáveis de Desigualdade System-GMM.

\begin{tabular}{lrrrrr}
\hline \multicolumn{1}{c}{ Variável } & Gini & L-Theil & Pobreza & $\begin{array}{c}\text { Extr. } \\
\text { Pobreza }\end{array}$ & $\frac{10 \% \text { Ricos }}{40 \% \text { Pobres }}$ \\
\hline Desigualdade & $-5,075^{* * *}$ & $-2,988^{*}$ & $-0,022$ & $0,011^{*}$ & $-0,002$ \\
Interação & $0,678^{* * *}$ & $0,359^{*}$ & 0,003 & $-0,00003^{*}$ & 0,000009 \\
\hline${ }^{* * *} p<0,01 ;{ }^{* *} p<0,05 ;{ }^{*} p<0,1$. & & & &
\end{tabular}

A Taxa de Extrema Pobreza apresentou coeficiente positivo, enquanto sua variável de Interação exibiu valor negativo. Os sinais contrários às demais medidas conflui com a hipótese de Attanasio e Binelli (2004) de que, dado um cenário de extrema pobreza (entendida como um baixo nível de renda individual), a desigualdade exerce efeito positivo no crescimento. A concentração de renda nesse ambiente configura-se como condição suficiente para a acumulação de capital, físico e humano. à medida que a renda agregada se eleva, verifica-se o efeito da incompletude dos mercados de crédito (Variável de Interação negativa).

Nota-se na Tabela 5, a título de exemplificação, que na regressão que adotou-se o método SystemGMM e o Gini de renda, obtêve-se um coeficiente $\beta_{1}=-0,168797 \in(-0,234767,-0,124732)$, o que corrobora com a metodologia proposta por Bond et al. (2001) na qual um estimador é considerado consistente quando o coeficiente $\beta_{1}$ encontra-se no intervalo entre os valores resultantes das estimações por MQO e Efeitos-Fixos. Na regressão com o $L$ de Theil, obtêve-se $\beta_{1}=-0,222484 \epsilon$ $(-0,230902,-0,128536)$. Os demais intervalos podem ser calculados consultando a Tabela 5.

Tabela 5. Coeficientes de $\beta_{1}$ MQO, System-GMM, Efeitos-Fixos e GMM.

\begin{tabular}{lccccc}
\hline \multicolumn{1}{c}{ Método } & Gini & L-Theil & Pobreza & $\begin{array}{c}\text { Extr. } \\
\text { Pobreza }\end{array}$ & $\frac{10 \% \text { Ricos }}{40 \% \text { Pobres }}$ \\
\hline MQO & $-0,12473^{* * *}$ & $-0,12854^{* * *}$ & $-0,12021^{* * *}$ & $-0,105773^{* *}$ & $-0,10867^{* *}$ \\
System-GMM & $-0,16879^{* * *}$ & $-0,22248^{* * * *}$ & $-0,21169^{* * *}$ & $-0,184824^{* *}$ & $-0,193142^{*}$ \\
Efeito-Fixo & $-0,34723^{* * *}$ & $-0,23090^{* * *}$ & $-0,23186$ & $-0,1996^{* * *}$ & $-0,200268^{* * *}$ \\
GMM & $-0,34723^{* * *}$ & $-0,36032^{* * *}$ & $-0,21423^{* * *}$ & $-0,21134^{* * *}$ & $-0,20982^{* * *}$ \\
\hline${ }^{* * *} p<0,01 ;{ }^{* *} p<0,05 ;{ }^{*} p<0,1$. & & & &
\end{tabular}

Bond et al. (2001, p.7) ressaltam que se o coeficiente de $\beta_{1}$ obtido pela técnica GMM for "muito próximo ou inferior à estimativa de Efeitos-Fixos parece provável que a estimativa GMM é também enviesada para baixo, talvez devido aos instrumentos fracos". A título de exemplificação, na regressão do Gini de Renda, o $\left|\beta_{1}\right|$ do estimador GMM está a uma distância de 0,222505 do $\left|\beta_{1}\right|$ obtido na estimação por MQO. Já a distância do $\left|\beta_{1}\right|$ oriundo do estimador de Efeitos-Fixos é menor e igual a 0,11247. A única regressão na qual o $\beta_{1}$ do GMM ficou entre os do MQO e do Efeitos-Fixos foi na regressão que considera a Taxa de Pobreza. No entanto, o coeficiente está mais próximo do de Efeitos-Fixos, quando comparado ao coeficiente do System-GMM. 
Com o intuito de atestar a validade das variáveis instrumentais utilizadas, aplicou-se o Teste de Sargan para sobre-identificação. Os Valores- $p$ da Estatística $J$ na Tabela 6 sugerem que os instrumentos utilizados em todas as regressões que adotaram o System-GMM são válidos, ou seja, não rejeitou-se a hipótese nula de que os instrumentos são não-correlacionados com o termo de erro, $\operatorname{Cov}\left[\boldsymbol{Z}_{i}^{+} \boldsymbol{\mu}_{i}\right]=0$, hipótese a qual foi rejeitada no método GMM.

Tabela 6. Valores- $P$ Teste de Sargan System-GMM e GMM.

\begin{tabular}{llllll}
\hline \multicolumn{1}{c}{ Variável } & Gini & L-Theil & Pobreza & $\begin{array}{c}\text { Extr. } \\
\text { Pobreza }\end{array}$ & $\frac{10 \% \text { Ricos }}{40 \% \text { Pobres }}$ \\
\hline System-GMM & 0,226666 & 0,160055 & 0,112700 & 0,155834 & 0,141097 \\
GMM & 0,0000 & 0,0000 & 0,0000 & 0,0000 & 0,0000 \\
\hline
\end{tabular}

Desse modo, as estimações do $\beta_{1}$ pelo método System-GMM, conforme metodologia proposta por Bond et al. (2001), encontram-se no intervalo entre os resultantes do MQO e Efeitos-Fixos, como visto na Tabela 5. Pode-se notar de forma intuitiva na Tabela 5 que, conforme apontado por Durlauf (2005), $p \lim \hat{\beta}_{\mathrm{EF}}<p \lim \hat{\beta}_{\mathrm{SYS}-\mathrm{GMM}}<p \lim \hat{\beta}_{\mathrm{MQO}}$. Além disso, como verificado na Tabela 6 , os resultados obtidos para o Teste de Sargan de sobre-identificação sugerem que os instrumentos mostraram-se válidos em todas as regressões nas quais empregou-se o método System-GMM. Tais fatos sugerem que a técnica SystemGMM mostrou-se assintóticamente não enviesada com variáveis instrumentais válidas, condições tidas como suficientes para que um estimador seja consistente, conforme apontado por Hsiao (2003). Com base nesses resultados, as hipóteses acerca dos efeitos da desigualdade no crescimento foram discutidas apenas com base nesse estimador.

\subsection{Discussão dos resultados — método System-GMM}

Como já dito no tópico anterior, a não-linearidade não foi rejeitada, como exposto na Tabela 7, o que corrobora com Voitchovsky (2005) e Barro $(2000,2008)$.

Pode ser observado na Tabela 8 que a variável Esperança de Vida apresentou sinal negativo, resultado repetido em todas as demais técnicas de estimação adotadas nesse estudo, o que contraria a teoria do crescimento. Mesmo que usualmente assuma-se que a Esperança de Vida impacte positivamente no crescimento, por ser uma proxy para saúde, caso admita-se a hipótese da instabilidade social, o efeito tende a possuir sinal contrário. Isso decorre da violência resultante da falta de estabilidade social aumentar os gastos com saúde e segurança, o que eleva o custo de vida geral dos indivíduos, além de direcionar recursos produtivos para atenuar os efeitos decorrentes do ambiente instável, efeitos confluentes com Bourguignon (2004).

Para analisar a hipótese da incompletude dos mercados, observou-se os coeficientes das variáveis Escolaridade Média e Analfabetismo, as quais constituem proxies para os efeitos da restrição do crédito no crescimento. Dada a incompletude dos mercados de crédito, credores buscam minimizar possíveis problemas de inadimplência. Um indivíduo de baixa renda, por não possuir dotação inicial suficiente, é impedido de acumular capital humano, o que subutiliza o seu potencial produtivo (Aghion \& Bolton, 1992, 1997; Ehrhart, 2009; Piketty, 1992, 1997). Isso implica em elevação dos custos de transação para elaborar e fiscalizar os contratos de forma a garantir os pagamentos. Devido ao aumento dos custos de transação, os investimentos realizados ficam condicionados diretamente à renda e aos ativos dos indivíduos, o que ocasiona distorções nos padrões de investimento. Os custos adicionais gerados resultam em um maior spread entre as taxas de juros do rentista e do tomador de crédito, o que faz com que o crédito se torne mais restrito à parcela da população de mais baixa renda (Banerjee \& Newman, 1993; Galor \& Zeira, 1993), uma vez que os investimentos em capital humano não possuem a liquidez necessária para servir como colateral (Carneiro \& Heckman, 2002). Esse mecanismo, associado às imperfeições do mercado de 


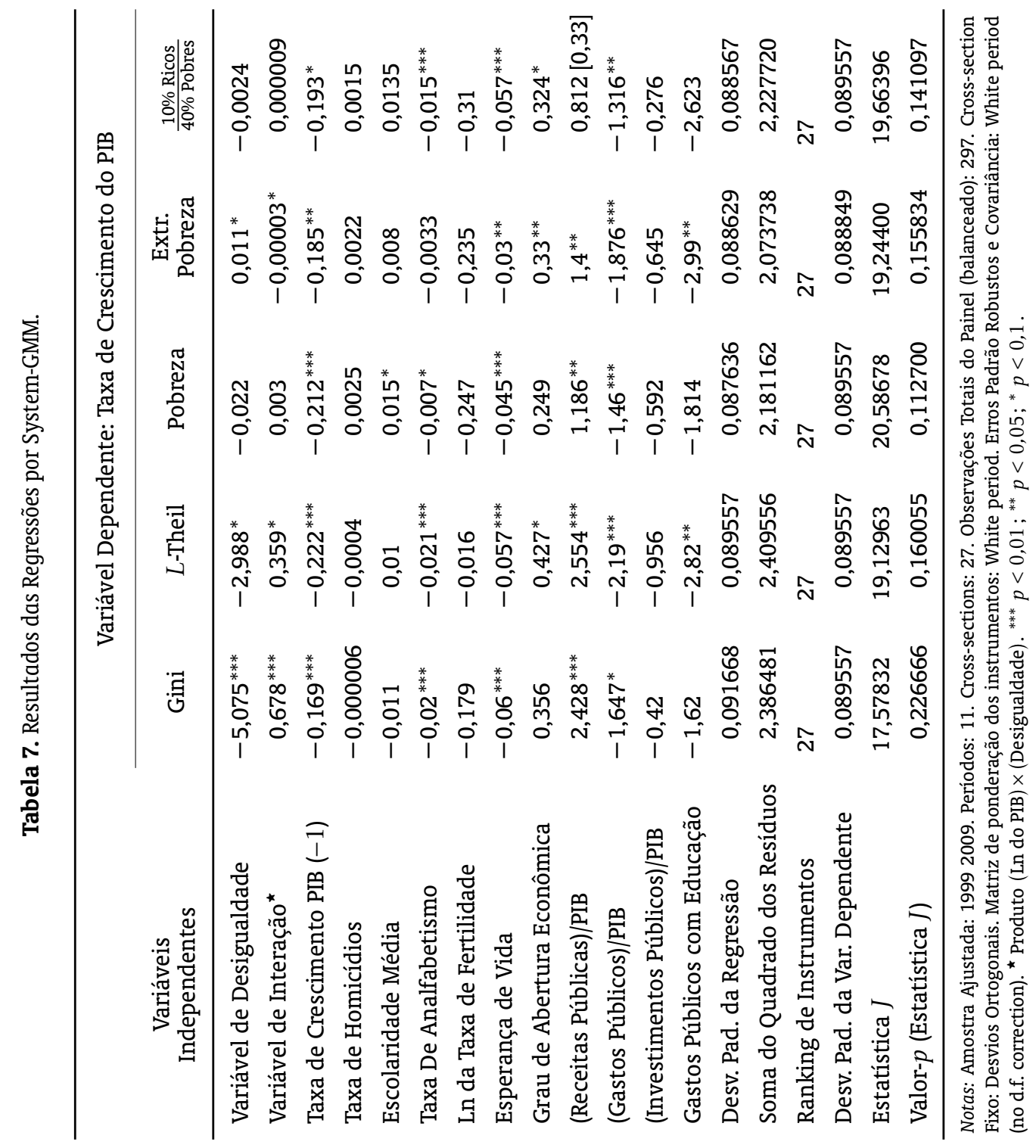


Tabela 8. Coeficientes da variável Esperança de Vida.

\begin{tabular}{cccccc}
\hline Variável & Gini & L-Theil & Pobreza & $\begin{array}{c}\text { Extr. } \\
\text { Pobreza }\end{array}$ & $\frac{10 \% \text { Ricos }}{40 \% \text { Pobres }}$ \\
\hline Esperança de Vida & $-0,0603^{* * *}$ & $-0,0567^{* * *}$ & $-0,0448^{* * *}$ & $-0,0303^{* *}$ & $-0,0569^{* * *}$ \\
\hline${ }^{* * *} p<0,01 ;{ }^{* *} p<0,05 ;{ }^{*} p<0,1$. & & & &
\end{tabular}

seguros, faz com que os investimentos não sejam destinados aos projetos mais rentáveis e sim aos mais seguros (Banerjee \& Newman, 1991).

Alesina e Rodrik (1994) encontraram evidencias empíricas que sugerem que o efeito da incompletude dos mercados na taxa de crescimento pode ser avaliado a partir dos níveis de escolaridade primária. Barro (2000) adotou níveis de escolaridade como uma de suas proxies para incompletude do mercado de créditos e evidenciou não-linearidade, com a desigualdade exercendo efeito positivo no crescimento dos países desenvolvidos e negativo nos demais. Barro (2008) investigou possíveis efeitos indiretos ao analisar a interação da desigualdade com a fertilidade (efeito positivo), democracia (efeito negativo) e ensino secundário (efeito negativo). Os resultados da interação das variáveis com o Gini não apresentaram significância estatística ou resultaram em coeficientes muito pequenos, sendo, desse modo, suplantados pelo efeito direto da desigualdade no crescimento (Barro, 2008).

Como verificado na Tabela 9, nossos resultados sugerem que a Taxa de Analfabetismo possui um coeficiente negativo e estatisticamente significativo, de forma que não é possível rejeitar a hipótese da incompletude dos mercados. Nesse caso, nossos resultados corroboram com evidências apresentadas por Carneiro e Heckman (2002) e Piketty (1997) nas quais indivíduos que não possuem qualificação mínima têm o seu potencial produtivo subutilizado, o que mitiga o crescimento.

Tabela 9. Coeficientes das Variáveis, Escolaridade Média e Taxa de Analfabetismo.

\begin{tabular}{lcccrc}
\hline Variável & Gini & L-Theil & Pobreza & \multicolumn{1}{c}{$\begin{array}{c}\text { Extr. } \\
\text { Pobreza }\end{array}$} & \multicolumn{1}{c}{$\frac{10 \% \text { Ricos }}{40 \% \text { Pobres }}$} \\
\hline Escolaridade & $-0,010768$ & 0,010359 & $0,015519^{*}$ & 0,007878 & \multicolumn{1}{c}{0,013517} \\
Analfabetismo & $-0,02042^{* * *}$ & $-0,02151^{* * *}$ & $-0,00662^{*}$ & $-0,003328$ & $-0,014882^{* * *}$ \\
\hline${ }^{* * *} p<0,01 ;{ }^{* *} p<0,05 ;{ }^{*} p<0,1$. & & & &
\end{tabular}

A hipótese da economia política foi testada pelas variáveis Receitas Públicas, Gastos Públicos, Investimentos Públicos e Gastos Públicos com Educação, e os valores seguem apresentados na Tabela 10. Dado o Teorema do Eleitor Mediano, a desigualdade implica em maior demanda por políticas redistributivas, o que desestimula a poupança, investimento e trabalho. Essa hipótese não foi rejeitada, dado o efeito negativo dos Gastos Públicos, o que corrobora com Alesina e Rodrik (1994). O sinal positivo das Receitas Públicas pode advir de sua correlação positiva com o crescimento, ou seja, à medida que a o PIB cresce, maior é o montante arrecadado pelos impostos. Desse modo, as evidências obtidas contradizem a ideia de que a redução da desigualdade por meio de políticas redistributivas é a característica que permite ao Brasil crescer à medida que se reduz a desigualdade.

Nesse trabalho visou-se controlar por outros dois efeitos com a inclusão do Grau de Abertura Econômica. Primeiro, o de que sociedades com baixa estabilidade social possuem menores capacidades de resposta a choques internacionais. Segundo, dado os influxos de investimentos internacionais, os agentes econômicos passam a ter acesso à tecnologia de ponta. Como nota-se na Tabela 11, os coeficientes obtidos nas regressões com o $L$ de Theil, Extrema Pobreza e (10\% Ricos)/(40\% Pobres) são positivos, o que corrobora com as evidências de Barro (2008) e Barro e Sala-i-Martin (1995) de que maior abertura 
Tabela 10. Coeficientes das Variáveis, Escolaridade Média e Taxa de Analfabetismo.

\begin{tabular}{lccccc}
\hline \multicolumn{1}{c}{ Variável } & Gini & L-Theil & Pobreza & $\begin{array}{c}\text { Extr. } \\
\text { Pobreza }\end{array}$ & $\frac{10 \% \text { Ricos }}{40 \% \text { Pobres }}$ \\
\hline Receitas Públicas & $2,4275^{* * *}$ & $2,5542^{* * *}$ & $1,186^{* *}$ & $1,3999^{* *}$ & 0,8119 \\
Gastos Públicos & $-1,6475^{*}$ & $-2,1894^{* * *}$ & $-1,4592^{* * *}$ & $-1,8763^{* * *}$ & $-1,3161^{* *}$ \\
Invest. Públicos & $-0,4204$ & $-0,9561$ & $-0,5920$ & $-0,6448$ & $-0,2761$ \\
Educação Pública & $-1,6198$ & $-2,8184^{* *}$ & $-1,8144$ & $-2,9873^{* *}$ & $-2,6235$ \\
\hline
\end{tabular}

${ }^{* * *} p<0,01 ;{ }^{* *} p<0,05 ;{ }^{*} p<0,1$.

econômica é benéfica ao crescimento.

Por fim, observa-se na Tabela 12 que o efeito isolado da desigualdade no crescimento no Brasil, derivado de (18) e mensurado pelo Gini de renda, mostra-se positivo, o que sugere que para os níveis de PIB per capita de 2009 a desigualdade foi positiva para o crescimento. Para que o efeito negativo suplantasse o positivo, seria necessário que o PIB assumisse o valor de R\$1.789,54 (Ano-base 2000). Dado um intervalo de confiança (nível de confiança de $99 \%)$, a média do Efeito está no intervalo $(0,71,1,02)$, o que sugere fortes indícios de que esse efeito seja positivo.

\section{CONCLUSÃO}

A presente pesquisa visou identificar o efeito da desigualdade no crescimento. De maneira distinta aos demais estudos, que valem-se em sua maioria de modelos com equação reduzida, estimou-se um modelo que incluiu variáveis de controle dos principais canais apontados pela teoria pelos quais a desigualdade afeta o crescimento. Devido a isso, acredita-se que o controle dos efeitos indiretos da desigualdade no crescimento foi efetuado com maior acuidade.

Partiu-se da premissa de que a desigualdade possui causalidade não-linear com o crescimento. Para verificar a existência de não-linearidade, incluiu-se como um dos regressores uma variável de interação entre desigualdade e o Ln do PIB per capita. Os resultados corroboraram com os de Barro $(2000,2008)$ e Voitchovsky (2005), nos quais a desigualdade exerce efeito positivo no crescimento para níveis de PIB per capita mais elevados (coeficiente da Variável de Interação) e efeito negativo nos de PIB baixo (coeficiente da Variável de Desigualdade). Isso contradiz a concepção teórica proposta por Bénabou (2000) e Galor (2010) de que o efeito da desigualdade no crescimento possui formato de U-invertido, confluindo com o questionamento de de Dominicis et al. (2008) à essa concepção. de Dominicis et al. (2008) arguem que o contexto atual dos países em desenvolvimento é distinto do vivenciado pelos países desenvolvidos, no qual esse modelo pôde ser verificado. Isso decorre do fato dos influxos de investimentos internacionais permitirem aos indivíduos de baixa renda o acesso à tecnologia de ponta, o que mitiga os efeitos positivos que a desigualdade exerce na acumulação de capital físico, dado um baixo PIB per capita. Sendo assim, a acumulação de capital humano seria a principal engrenagem do crescimento, mesmo sem a presença de um alto PIB per capita.

Tabela 11. Coeficientes da Variável Grau de Abertura Econômica.

\begin{tabular}{cccccc}
\hline Variável & Gini & L-Theil & Pobreza & $\begin{array}{c}\text { Extr. } \\
\text { Pobreza }\end{array}$ & $\frac{10 \% \text { Ricos }}{40 \% \text { Pobres }}$ \\
\hline Abertura Econômica & 0,35629 & $0,427269^{*}$ & 0,248703 & $0,3304366^{* *}$ & $0,323839^{*}$ \\
\hline${ }^{* * *} p<0,01 ;{ }^{* *} p<0,05 ;{ }^{*} p<0,1$. & & & &
\end{tabular}


Tabela 12. Efeito da Desigualdade no Crescimento Derivado da Equação (18) — PIB 2009 (Ano-base 2000).

\begin{tabular}{lrl|lrr}
\hline \multicolumn{1}{c}{ Descrição } & $\begin{array}{c}\text { PIB per capita } \\
(\mathrm{R} \text { ) }\end{array}$ & Efeito & Descrição & $\begin{array}{c}\text { PIB per capita } \\
\text { (RS) }\end{array}$ & Efeito \\
\hline Break Even Negativo & $1.789,54$ & $-2,2 \mathrm{E}-7$ & Região Norte & $5.131,34$ & 0,713773 \\
Break Even Positivo & $1.789,55$ & $3,57 \mathrm{E}-6$ & Acre & $5.161,12$ & 0,717694 \\
Brasil & $8.169,78$ & 1,028901 & Amapá & $5.706,41$ & 0,785749 \\
Região Sudeste & $10.695,21$ & 1,211412 & Amazonas & $7.060,66$ & 0,930039 \\
Espírito Santo & $9.245,48$ & 1,112714 & Pará & $3.795,32$ & 0,509415 \\
Minas Gerais & $6.919,50$ & 0,916356 & Rondônia & $6.497,88$ & 0,873757 \\
Rio de Janeiro & $10.673,85$ & 1,210057 & Roraima & $6.408,50$ & 0,864372 \\
São Paulo & $12.653,43$ & 1,325336 & Tocantins & $5.446,16$ & 0,754119 \\
Região Nordeste & $3.944,33$ & 0,535509 & Região Centro-Oeste & $10.800,20$ & 1,218031 \\
Alagoas & $3.249,15$ & 0,404135 & Distrito Federal & $24.357,46$ & 1,769093 \\
Bahia & $4.522,35$ & 0,628171 & Goiás & $6.976,51$ & 0,921915 \\
Ceará & $3.711,98$ & 0,49437 & Mato Grosso & $9.217,53$ & 1,110662 \\
Maranhão & $3.022,77$ & 0,3552 & Mato Grosso do Sul & $7.440,24$ & 0,965521 \\
Paraíba & $3.678,70$ & 0,488268 & Região Sul & $9.332,15$ & 1,119036 \\
Pernambuco & $4.298,87$ & 0,593831 & Paraná & $8.585,79$ & 1,062555 \\
Piaú & $2.922,16$ & 0,332263 & Rio Grande do Sul & $9.551,27$ & 1,134762 \\
Rio Grande do Norte & $4.294,99$ & 0,593219 & Santa Catarina & $10.244,80$ & 1,182258 \\
Sergipe & $4.726,41$ & 0,658075 & & & \\
\hline
\end{tabular}

Não rejeitou-se também a hipótese da incompletude dos mercados de crédito, diante dos coeficientes negativos e significantes estatisticamente da Taxa de Analfabetismo em todas as regressões que empregaram o método System-GMM. Desse modo, as evidências sugerem que, dada a impossibilidade de se investir em educação devido principalmente ao crédito restrito, a parcela de indivíduos sem a qualificação mínima requerida pelo mercado mitiga as taxas de crescimento do PIB per capita. O argumento da economia política, dado o Teorema do Eleitor Mediano, também não foi rejeitado. Os coeficientes dos Gastos Públicos mostraram-se negativos e significantes estatisticamente, mesmo mensurando-se a desigualdade por cinco medidas distintas. Assim, as evidências sugerem que a pressão exercida pela sociedade por mais políticas redistributivas como forma de atenuar os efeitos da distinção de renda implicam em um impacto negativo na taxa de crescimento. Isso contraria a concepção de que a política redistributiva brasileira é a característica distintiva que permite ao país crescer e reduzir desigualdade concomitantemente. Essa dinâmica parece advir do fato de que a desigualdade exerce efeito negativo no crescimento para níveis de baixo PIB per capita.

A análise em um único país apresentou evidências de que os problemas de comparabilidade de dados em Atkinson e Brandolini (2009) e Banerjee e Duflo (2003) foram mitigados. Além disso, a adoção de um modelo que incluiu variáveis de controle dos principais canais pelos quais a desigualdade pode afetar o crescimento mostrou-se eficiente diante do problema ressaltado por Voitchovsky (2005), no qual a técnica econométrica pode influenciar o sinal do resultado obtido. Os resultados obtidos sugerem que tanto as técnicas que valem-se mais da variação das séries temporais (e quetendem a indicar efeito positivo da desigualdade) quanto os métodos que utilizam mais os dados cross-section (e que tendem a indicar efeito negativo) apresentaram os mesmos sinais, apenas com diferença na magnitude do efeito.

Foi possível também, após estimar-se por quatro técnicas econométricas distintas, tecer considerações acerca dos estimadores. Corroborando com a literatura (Bond et al., 2001; Durlauf, 2005), ao analisar-se os coeficientes do termo auto-regressivo, o método MQO em Painel com AR(1) apresentou 
viés para cima (Hsiao, 2003; Nerlove, 1967; Trognon, 1978). A técnica dos Efeitos-Fixos mostrou-se enviesada para baixo (Anderson \& Hsiao, 1982; Nerlove, 1971; Nickell, 1981). Já com relação ao estimador GMM, devido à fraca instrumentalização, obteve-se resultados próximos aos dos Efeitos-Fixos. Por fim, a estimação por System-GMM, de forma intuitiva, apresentou evidencias que atenderam aos critérios de consistências em (17) e ao Teste de Sargan de sobre-identificação.

Admitindo-se a validade das premissas sobre a interação entre desigualdade, fertilidade e educação, tem-se um fato interessante para o caso brasileiro, o qual sugere-se exploração em estudos futuros. Dado que os agentes econômicos com baixa renda possuem incentivos ao aumento do número de filhos como forma alternativa para elevar a renda familiar, tem-se um efeito negativo no crescimento devido ao baixo acumulo de capital humano. As políticas redistributivas brasileiras ocasionariam um incentivo adicional a esse movimento. Pelo fato de programas como o Bolsa Escola condicionarem à assistência a frequência das crianças na escola, tem-se um desincentivo às famílias com baixa renda a buscarem qualificação fora da rede pública. Os coeficientes dos Gastos Públicos com Educação, na estimação pelo System-GMM, para o $L$ de Theil $\left(-2,818^{* *}\right)$ e para a Taxa de Pobreza Extrema $\left(-2,987^{* *}\right)$, mostram evidências que sugerem tal possibilidade.

\section{REFERÊNCIAS BIBLIOGRÁFICAS}

Aghion, P., \& Bolton, P. (1992). Distribution and growth in models of imperfect capital markets. European Economic Review, 36(2-3), 603-611.

Aghion, P., \& Bolton, P. (1997). A theory of trickle-down growth and development. Review of Economic Studies, 64(2), 151-172.

Aghion, P., Caroli, E. \& Garcia-Penalosa, C. (1999). Inequality and economic growth: The perspective of the new growth theories. Journal of Economic Literature, 37(4), 1615-1660. doi: 10.1257/jel.37.4.1615

Alesina, A., \& Perotti, R. (1996). Income distribution, political instability, and investment. European Economic Review, 40(6), 1203-1228.

Alesina, A., \& Rodrik, D. (1994). Distributive politics and economic growth. Quarterly Journal of Economics, 109(2), 465-490. doi: $10.2307 / 2118470$

Anderson, T. W., \& Hsiao, C. (1982). Formulation and estimation of dynamic models using panel data. Journal of Econometrics, 18(1), 47-82. doi: 10.1016/0304-4076(82)90095-1

Arellano, M., \& Bond, S. R. (1991). Some tests of specification for panel data: Monte Carlo evidence and an application to employment equations. Review of Economic Studies, 58(2), 277-297. doi: 10.2307/2297968

Arellano, M., \& Bover, O. (1995). Another look at the instrumental variable estimation of error-components models. Journal of Econometrics, 68(1), 29-51. doi: 10.1016/0304-4076(94)01642-D

Atkinson, A. B., \& Brandolini, A. (2009). On data: A case study of the evolution of income inequality across time and across countries. Cambridge Journal of Economics, 33(3), 381-404. doi: 10.1093/cje/bel013

Attanasio, 0., \& Binelli, C. (2004). Inequality, growth and redistributive policies. In Poverty, inequality and growth: Proceedings of the AFD-EUDN Conference, 2003 (pp. 179-223). Paris. Disponivel em: http://www.afd.fr/webdav/site/afd/shared/PUBLICATIONS/RECHERCHE/Archives/Notes -et-documents/10-notes-documents.pdf

Banerjee, A. V., \& Duflo, E. (2003). Inequality and growth: What can the data say? Journal of Economic Growth, 8(3), 267-299. doi: 10.1023/A:1026205114860

Banerjee, A. V., \& Newman, A. (1993). Occupational choice and the process of development. Journal of Political Economy, 101(2), 274-298. Disponível em: http://EconPapers.repec.org/RePEc:ucp:jpolec:v:101:y:1993:i:2:p: 274-98

Banerjee, A. V., \& Newman, A. F. (1991). Risk-bearing and the theory of income distribution. Review of Economic Studies, 58(2), 211-235. doi: 10.2307/2297965

Barro, R. J. (2000). Inequality and growth in a panel of countries. Journal of Economic Growth, 5(1), 5-32. doi: 10.1023/A:1009850119329 
Barro, R. J. (2008, Jan). Inequality and growth revisited (Working Papers on Regional Economic Integration $\left.\mathrm{N}^{0} 11\right)$. Asian Development Bank. Disponível em: http://ideas.repec.org/p/ris/adbrei/0011.html

Barro, R. J., \& Sala-i-Martin, X. (1995). Economic growth. New York: McGraw-Hill.

BBC Brasil. (2011, dezembro 05). Apesar de redução, Brasil mantém maior desigualdade entre Brics, diz OCDE. Mediacon news. Acessado em 11 de maio de 2012: http://www.midiacon.com.br/materia.asp?id_canal= 5\&id $=41881$

BBC Brasil. (2012, janeiro 19). Brasil é o segundo país com maior desigualdade do G20, de acordo com um estudo realizado nos países que compoem o grupo. BBC Brasil. Acessado em 11 de maio de 2012: http://www.bbc .co.uk/portuguese/noticias/2012/01/120118_desigualdade_pesquisa.shtml

Black, D. (1948). On the rationale of group decision-making. Journal of Political Economy, 56(1), 23-34. Disponível em: http://www.jstor.org/stable/1825026

Blundell, R., \& Bond, S. (1998). Initial conditions and moment restrictions in dynamic panel data models. Journal of Econometrics, 87(1), 115-143. doi: 10.1016/S0304-4076(98)00009-8

Bond, S., Hoeffler, A. \& Temple, J. (2001, Sept). GMM estimation of empirical growth models (Discussion Paper Series $\mathrm{N}^{0}$ 2001-W21). Economics Group, Nuffield College, University of Oxford. Disponível em: http://www .nuffield.ox.ac.uk/economics/papers/2001/w21/bht10.pdf

Bourguignon, F. (1981). Pareto superiority of unegalitarian equilibria in Stiglitz' model of wealth distribution with convex saving function. Econometrica, 49(6), 1469-1475. doi: http://www.jstor.org/stable/1911412

Bourguignon, F. (2004, Mar). The poverty-growth-inequality triangle (Working Paper $\left.\mathrm{N}^{0} 125\right)$. New Delhi, India: Indian Council for Research on International Economic Relations. Disponível em: http://siteresources .worldbank.org/INTPGI/Resources/342674-1206111890151/15185 ICRIER paper-final.pdf

Brock, W. A., \& Durlauf, S. N. (2001). What have we learned from a decade of empirical research on growth? Growth empirics and reality. World Bank Economic Review, 15(2), 229-271. doi: 10.1093/wber/15.2.229

Bun, M., \& Kleibergen, F. (2010, April 9). GMM based inference for panel data models. Paper presented at the 2nd Amsterdam-Bonn Workshop in Econometrics, Amsterdam, NL. Disponível em: https://editorialexpress.com/ cgi-bin/conference/download.cgi?db_name $=$ paneldata2010\&paper_id $=72$

Bénabou, R. (2000). Unequal societies: Income distribution and the social contract. American Economic Review, 90(1), 96-129. doi: 10.1257/aer.90.1.96

Carneiro, P., \& Heckman, J. J. (2002). The evidence on credit constraints in post-secondary schooling. The Economic Journal, 112(482), 989-1018. doi: 10.1111/1468-0297.00075

Clarke, G. R. G. (1995). More evidence on income distribution and growth. Journal of Development Economics, 47(2), 403-427. doi: 10.1016/0304-3878(94)00069-0

Deininger, K., \& Okidi, J. (2003). Growth and poverty reduction in Uganda, 1999-2000: Panel data evidence. Development Policy Review, 21(4), 481-509. doi: 10.1111/1467-7679.00220

Deininger, K., \& Squire, L. (1996). A new data set measuring income inequality. World Bank Economic Review, 10(3), 565-591. doi: 10.1093/wber/10.3.565

Deininger, K., \& Squire, L. (1998). New ways of looking at old issues: Inequality and growth. Journal of Development Economics, 57(2), 259-287. doi: 10.1016/S0304-3878(98)00099-6

de Dominicis, L., Florax, R. J. G. M. \& de Groot, H. L. F. (2008). A meta-analysis on the relationship between income inequality and economic growth. Scottish Journal of Political Economy, 55(5), 654-682. doi: 10.1111/j.14679485.2008.00470.x

Durlauf, S. (2005). Growth econometrics. In P. Aghion \& S. N. Durlauf (Eds.), Handbook of economic growth (Vol. 1, pp. 555-677). Elsevier.

Ehrhart, C. (2009, Feb). The effects of inequality on growth: A survey of the theoretical and empirical literature (Working Paper $\mathrm{N}^{0}$ WP 2009 - 107). ECINEQ, Society for the Study of Economic Inequality. Disponível em: http://www.ecineq.org/milano/WP/ECINEQ2009-107.pdf

Fielding, D., \& Torres, S. (2006). A simultaneous equation model of economic development and income inequality. The Journal of Economic Inequality, 4(3), 279-301. doi: 10.1007/s10888-005-9016-2

Fishlow, A. (1996). Inequality, poverty and growth: Where do we stand? In M. Bruno \& B. Pleskovic (Eds.), Annual world bank conference on development economics 1995 (pp. 25-39). Washington, D.C.: The 
World Bank. Disponível em: http://documents.worldbank.org/curated/en/1996/05/696570/annual-world -bank-conference-development-economics-1995

Fleck, I. (2012, abril 2012). Para nobel de economia, Brasil é exemplo para China e Índia. Folha/UOL. Acessado em 2 de maio de 2012: http://www1.folha.uol.com.br/fsp/mundo/39157-paranobel-de-economia-brasil -e-um-exemplo-para-china-e-india.shtml

Forbes, K. J. (2000). A reassessment of the relationship between inequality and growth. American Economic Review, 90(4), 869-887. doi: 10.1257/aer.90.4.869

Galor, O. (2010). The 2008 Lawrence R. Klein lecture-Comparative Economic Development: insights from unified growth theory. International Economic Review, 51(1), 1-44. doi: 10.1111/j.1468-2354.2009.00569.x

Galor, O., \& Zeira, J. (1993). Income distribution and macroeconomics. The Review of Economic Studies, 60(1), 35-52. doi: $10.2307 / 2297811$

Gregorio, J. D., \& Lee,J.-W. (2004). Growth and adjustment in East Asia and Latin America. Economia, 5(1), 69-134.

Griffin, K., \& Ickowitz, A. (1997, Nov). The distribution of wealth and the pace of development (Working Paper $\mathrm{N}^{0}$ 3). United Nations Development Programme, Social Development and Poverty Elimination Division.

Gupta, D. K. (1990). The economics of political violence: The effect of political instability on economic growth. New York: Praeger Publishers.

Hsiao, C. (2003). Analysis of panel data (2nd ed.). Cambridge University Press. doi: 10.1017/CB09780511754203

Iradian, G. (2005, Feb). Inequality, poverty, and growth: Cross-country evidence (IMF Working Paper $\mathrm{N}^{0}$ 05/28). International Monetary Fund. Disponível em: http://www.imf.org/external/pubs/ft/wp/2005/wp0528.pdf

Kaldor, N. (1955-1956). Alternative theories of distribution. The Review of Economic Studies, 23(2), 83-100. Disponível em: http://www.jstor.org/stable/2296292

Kaldor, N. (1957). A model of economic growth. The Economic Journal, 67(268), 591-624. Disponível em: http:// www.jstor.org/stable/2227704

Keefer, P., \& Knack, S. (2002). Polarization, politics and property rights: Links between inequality and growth. Public Choice, 111(1-2), 127-154. doi: 10.1023/A:1015168000336

Keynes, J. M. (1920). The economic consequences of the peace. New York: Harcourt, Brace, and Howe.

Knowles, S. (2005). Inequality and economic growth: The empirical relationship reconsidered in the light of comparable data. Journal of Development Studies, 41(1), 135-159. doi: 10.1080/0022038042000276590

Li, H., \& Zou, H.f. (1998). Income inequality is not harmful for growth: Theory and evidence. Review of Development Economics, 2(3), 318-334. doi: 10.1111/1467-9361.00045

Loury, G. (1981). Intergenerational transfers and the distribution of earnings. Econometrica, 49(4), 843-67. Disponível em: http:/|EconPapers.repec.org/RePEc:ecm:emetrp:v:49:y:1981:i:4:p:843-67

Lucas, R. E., Jr. (2002). Lectures on economic growth. Harvard University Press.

Mirrlees, J. (1971). An exploration in the theory of optimum income taxation. Review of Economic Studies, 38(114), 175-208. Disponível em: http://EconPapers.repec.org/RePEc:bla:restud:v:38:y:1971:i:114:p:175-208

Nancy, B., Ross, D. \& Sabot, R. (1995). Inequality and growth reconsidered: Lessons from East Asia. The World Bank Economic Review, 9(3), 477-508. doi: 10.1093/wber/9.3.477

Nerlove, M. (1967). Experimental evidence on the estimation of dynamic economic relations from a time series of cross-sections. The Economic Studies Quarterly, 18(3), 42-74. Disponível em: http://cowles.econ.yale.edu/ $\mathrm{P} / \mathrm{cp} / \mathrm{p} 02 \mathrm{~b} / \mathrm{p} 0266 . \mathrm{pdf}$

Nerlove, M. (1971). Further evidence on the estimation of dynamic economic relations from a time series of cross sections. Econometrica, 39(2), 359-382. Disponível em: http://www.jstor.org/stable/1913350

Nerlove, M. (1999). Properties of alternative estimators of dynamic panel models: An empirical analysis of crosscountry data for the study of economic growth. In G. S. Maddala \& C. Hsiao (Eds.), Analysis of panels and limited dependent variable models. Cambridge, UK: Cambridge University Press.

Nickell, S. J. (1981). Biases in dynamic models with fixed effects. Econometrica, 49(6), 1417-1426. Disponível em: http://www.jstor.org/stable/1911408

Otter, T. (2009, April). Does inequality harm income mobility and growth? An assessment of the growth impact of income and education inequality in Paraguay 1992-2002 (IAI Discussion Paper $\mathrm{N}^{0}$ 188). Ibero-America Institute for Economic Research. Disponível em: http://EconPapers.repec.org/RePEc:got:iaidps:188 
Panizza, U. (2002). Income inequality and economic growth: Evidence from american data. Journal of Economic Growth, 7(1), 25-41. doi: 10.1023/A\%3A1013414509803

Perotti, R. (1996). Growth, income distribution, and democracy: What the data say. Journal of Economic Growth, 1(2), 149-187. doi: 10.1007/BF00138861

Persson, T., \& Tabellini, G. (1994). Is inequality harmful for growth? The American Economic Review, 84(3), 600-621. Disponível em: http://www.jstor.org/stable/2118070

Piketty, T. (1992). Imperfect capital markets and persistence of initial wealth inequalities (Discussion Paper $\mathrm{N}^{0}$ $\mathrm{TE} / 92 / 255)$. London School of Economics and Political Science-The Suntory and Toyota International Centres for Economics and Related Disciplines. Disponivel em: http://eprints.lse.ac.uk/19371/

Piketty, T. (1997). The dynamics of the wealth distribution and the interest rate with credit rationing. Review of Economic Studies, 64(2), 173-189. Disponível em: http://EconPapers.repec.org/RePEc:bla:restud:v:64:y:1997: i:2:p:173-89

Pinkovskiy, M., \& Sala-i-Martin, X. (2009, October). Parametric estimations of the world distribution of income (Working Paper $\mathrm{N}^{0}$ 15433). National Bureau of Economic Research. doi: 10.3386/w15433

Rao, C. R. (1973). Linear statistical inference and its applications (2nd ed.). New York: Wiley.

Roodman, D. (2009). A note on the theme of too many instruments. Oxford Bulletin of Economics and Statistics, 71(1), 135-158. doi: 10.1111/j.1468-0084.2008.00542.x

Schipper, Y., \& Hoogeveen, J. G. (2005, May). Which inequality matters? Growth evidence based on small area welfare estimates in Uganda (Policy Research Working Paper $\mathrm{N}^{0}$ WPS 3592). Washington, DC: World Bank. Disponível em: http://documents.worldbank.org/curated/en/2005/05/5800534/inequality-matters -growth-evidence-based-small-area-welfare-estimates-uganda

Sierminska, E., Brandolini, A. \& Smeeding, T. (2006). The Luxembourg Wealth Study: A cross-country comparable database for household wealth research. The Journal of Economic Inequality, 4(3), 375-383. doi: 10.1007/s10888-006-9030-z

Temple, J. (1999). The new growth evidence. Journal of Economic Literature, 37(1), 112-156. doi: 10.1257/jel.37.1.112

Tower, C. (2012, Mar 12). BOC's Macklem: Brazil shows the way on growth, lower inequality. MNI/Deutsche Börse Group. Acessado em 11 de maio de 2012: https://mninews.marketnews.com/content/bocs-macklem-brazil -shows-way-growthlower-inequality

Trognon, A. (1978). Miscellaneous asymptotic properties of ordinary least squares and maximum likelihood estimators in dynamic error components models. Annales de l'INSEE, 30/31(The Econometrics of Panel Data), 631-657. doi: http://www.jstor.org/stable/20075306

Voitchovsky, S. (2005). Does the profile of income inequality matter for economic growth? Distinguishing between the effects of inequality in different parts of the income distribution. Journal of Economic Growth, 10(3), 273-296. doi: 10.1007/s10887-005-3535-3 